\title{
Graphene-Based Materials for Photoanodes in Dye-Sensitized Solar Cells
}

\author{
Xiaoru Guo ${ }^{1}$, Ganhua Lu ${ }^{2}$ and Junhong Chen ${ }^{1 *}$ \\ ${ }^{1}$ Department of Mechanical Engineering, University of Wisconsin-Milwaukee, Milwaukee, WI, USA, ${ }^{2}$ Department of \\ Mechanical Engineering, University of Alaska Anchorage, Anchorage, AK, USA
}

This article reviews the research on the use of graphene and related materials in the photoanode of dye-sensitized solar cells (DSSCs). Graphene-based materials, such as pristine graphene, graphene oxide, and reduced graphene oxide, have properties attractive for various components of the DSSC photoanode. We first provide a brief introduction to graphene properties and analyze requirements for making a high-performance photoanode. Then, we introduce applications of graphene-based materials in each part of the DSSC photoanode, i.e., the transparent conducting electrode, the sensitizing material, and the semiconducting layer. Particularly, we discuss how the incorporation of graphene-based materials in those components can enhance the photoanode performance. It is clear that the outstanding properties of graphene, such as the fast electron transfer ability, high Young's modulus, and good transparency, benefit DSSC photoanode research, and doping or surface modifications of graphene nanosheets with other materials can also improve the photoanode and, thus, the resulting cell performance. Finally, we present an outlook for current issues and further trends for using graphene materials in DSSC photoanodes.

Keywords: dye-sensitized solar cells, DSSCs, photoanodes, graphene, reduced graphene oxide, graphene oxide

\section{INTRODUCTION}

It has become an important and urgent issue to seek clean and sustainable alternatives for fossil fuels because of the diminishing supply of these fuels, the ever-increasing demand for energy, and the environmental challenges associated with fossil fuel consumption. Many types of renewable energies (e.g., solar, wind, and hydraulic energies) have been actively explored, and related technologies for energy conversion and storage have been developed and/or commercialized for building a "sustainable energy future" (Chu and Majumdar, 2012). Solar energy is an abundant, unlimited, and clean source and has been widely considered as one of the top options among renewable energy sources. However, since solar energy has relatively low energy density (i.e., power per unit area), the realistic and competitive employment of solar cells requires a large-scale collection area and/or high efficiency.

So far, three generations of solar cells have been developed (Green, 2001; Goetzberger et al., 2003; Jayawardena et al., 2013). Silicon-based p-n junction photovoltaic (PV) cells, including polysilicon and monocrystalline $\mathrm{Si}$ cells, are the first generation solar cells, which have high efficiency but are expensive to manufacture for reasons such as the very high temperature (over $1600{ }^{\circ} \mathrm{C}$ ) required to obtain Si by reducing silica. Despite the continuous improvement in the fabrication process, the 
energy that a Si-based PV cell can generate in its lifetime is still less than that needed to fabricate it (Ahmad et al., 2013). To overcome the high cost issue for Si PV cells, thin-film solar cells with low cost (or the second-generation solar cells) were developed using inexpensive amorphous silicon and other semiconducting materials; however, the efficiency of the second-generation solar cells is relatively low compared with the Si cells (Goetzberger et al., 2003; Jayawardena et al., 2013). The third-generation solar cells have been explored with the aim to achieve both low cost and relatively high efficiency. Among the technologies for the emerging third-generation solar cells, dye-sensitized solar cells (DSSCs) are considered as a technically and economically viable option, particularly in comparison with Si-based $\mathrm{p}-\mathrm{n}$ junction PV devices (Green, 2001).

The general model of a DSSC, initially proposed and developed by Michael Graetzel in 1991, is a liquid junction device that consists of a nanocrystalline $\mathrm{TiO}_{2}$ photoanode, an iodine redox $\left(\mathrm{I}_{3}^{-} / \mathrm{I}^{-}\right)$pair electrolyte, and a counter electrode (CE) (also called cathode) typically made of a thin film of Pt. The same group modified the initial DSSC design and further developed a monolithic architecture in 1996, in which the CE was moved to the photoanode side and separated from the photoanode with a thin spacer of insulating material. The monolithic design reduced the cost of transparent conductive material (Kay and Gratzel, 1996). The sandwiched structure of a DSSC is shown in Figure 1. The whole cell is mechanically supported by transparent conductive materials, such as conductive polymers, indium tin oxide (ITO) glass, and fluorine-doped tin oxide (FTO) glass. Inside the cell, a monolayer of dye molecules, attached on semiconducting materials (typically $\mathrm{TiO}_{2}$ ), is hosted on the photoanode; electrocatalyst material on a CE (cathode in Figure 1) is separated from the photoanode by an electrolyte with a selected redox mediator. The operating cycle of the DSSC starts with sensitizers (dye in Figure 1) absorbing photons, leading to the injection of electrons from excited dye $\left(\mathrm{S}^{\star}\right)$ molecules to the conduction band of large bandgap semiconducting materials $\left(\mathrm{TiO}_{2}\right.$ in Figure 1). After

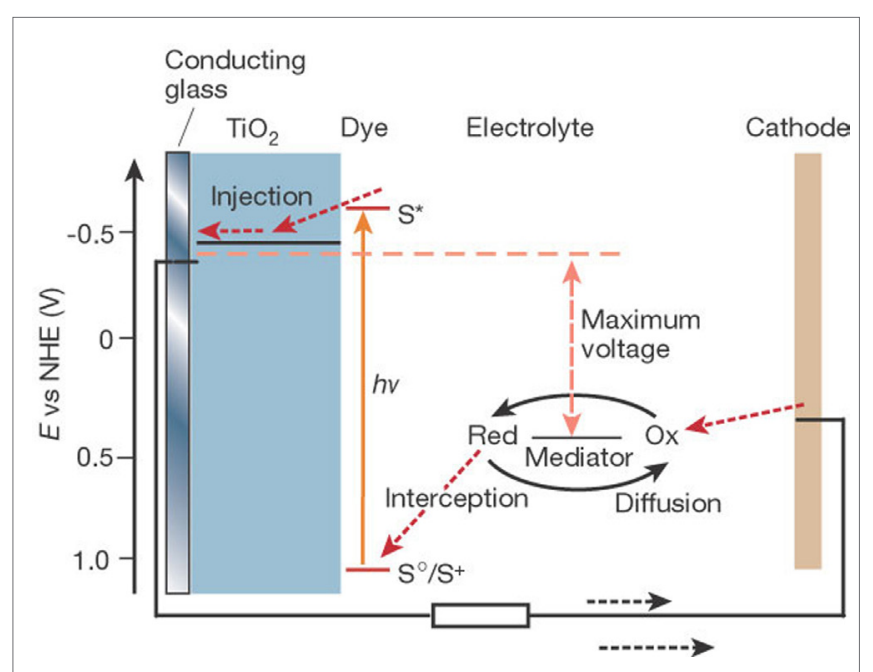

FIGURE 1 | DSSC working principles (Gratzel, 2001). Copyright Nature Publishing Group, 2001. diffusing in the current collector and transferring in conducting glass, the electrons are returned through an external circuit to the electrolyte or hole conductor by electrocatalyst materials at the CE. The mediators in the electrolyte or hole conductor finally complete the circuit with a reduction reaction to regenerate dye molecules (Nazeeruddin et al., 2011). Among all types of solar cells, the DSSC is the kind that separates photon absorption and charge transportation during photoelectric conversion, mimicking the photosynthesis process in the green leaves of plants (Gratzel, 2009). This separation yields significant advantage for improving the DSSC design, since all cell elements can be analyzed and optimized individually (Ahmad et al., 2013).

In the past two decades, a lot of works have been done on each and every part of the DSSC to improve its performance. From the materials perspective, new materials and conventional materials with novel morphologies and structures have been explored extensively for each component in the DSSC. For example, various less expensive alternatives, such as cobalt sulfide $(\mathrm{CoS})$, have been studied as the catalytic material to replace expensive platinum (Pt) in the CE (Wang et al., 2009, 2010); all-solid-state DSSCs were fabricated and reported to reach high efficiency (Chung et al., 2012); more recently, perovskite material was introduced into solar cell study and raised the lab efficiency record to $20.1 \%$ (Burschka et al., 2013; Zhou et al., 2014; Jeon et al., 2015).

The photoanode serves as the overall energy conversion center and, thus, plays a critical role in the DSSC. As shown in Figure 1, the photoanode is composed of three essential components: a conducting substrate, a layer of semiconducting material, and sensitizers. The conducting substrate is generally transparent so that light can pass through to the sensitizers. Typical candidates for the conducting substrate include conducting glass (i.e., glass coated with ITO or FTO) and conductive polymers. To ensure the cell performance, the conducting substrate is required to have high light transparency, high mechanical strength, and low surface resistivity. It should be noted that opaque substrates (e.g., metal foils) are used occasionally for the photoanode due to the limitations of some photoanode manufacturing processes; in these rare cases, light comes into the cell through the CE (Kalyanasundaram, 2010).

To achieve efficient electron transport, the semiconducting layer optimally should have a large bandgap, good conductivity and stability, and appropriate morphological structure to maximize sensitizer loading. Many wide-bandgap oxide semiconductors have been investigated in the DSSC photoanode, including $\mathrm{TiO}_{2}, \mathrm{ZnO}$, and $\mathrm{SnO}_{2}$. These semiconducting materials are usually structured to provide a high surface area for increasing the loading of sensitizing material. Using $\mathrm{TiO}_{2}$ nanoparticles as an example, particles at $\sim 400 \mathrm{~nm}$ are usually used as a scattering layer to enhance photon absorption, and particles at $\sim 20 \mathrm{~nm}$ are used to create a mesoporous structure (Zhang et al., 2007; Haynes et al., 2011). Additionally, $\mathrm{TiO}_{2}$ can absorb ultraviolet (UV) light and, thus, serves as a protector for organic dyes that are instable under UV illumination (Hagfeldt et al., 2010).

For sensitizers, thousands of different sized organic molecules have been introduced, and they are commonly based on big $\pi$-conjugation (Ahmad et al., 2013; Yang et al., 2014), such as N719 and N3. Different from traditional sensitizers, perovskite materials are cubic crystals and have outstanding performance 
and stability (Kojima et al., 2009; Etgar et al., 2012; Burschka et al., 2013). All sensitizers are generally designed and optimized to have high absorption at the visible light band, up to a wavelength at $\sim 800 \mathrm{~nm}$ (Nazeeruddin et al., 1999; Kalyanasundaram, 2010).

Because the photoanode is at the core of the photon-electron conversion process, improvements of the photoanode design are crucial for building high-performance DSSCs. Generally, key factors to be considered in developing DSSC photoanodes are as follows: transparency and electron collection of electrodes, photo-electron generation rate, electron injection, diffusion and transfer ability, and charge carrier recombination rate. Transparent conducting oxides (TCOs) (e.g., ITO and FTO) have been widely used in conducting substrates because they offer good transparency and electron collection rate; however, the cost of TCOs is relatively high. Photo-electron generation is dependent on the electronic properties of sensitizers. Optimizing the band structure of sensitizers can improve the photon-electron conversion process and especially maximize the extinction coefficients in the near-IR region (Hagfeldt et al., 2010). Electron mobility is closely related to the semiconducting layer; to preserve high electron mobility, it is preferred to have small electron injection barriers between the sensitizer and the semiconducting layer, a long diffusion distance, and a fast transfer ability (Hagfeldt et al., 2010). The charge carrier recombination rate depends on the whole kinetics of electron removal and recovery and can be found by calculating the exciton lifetime (Hagfeldt et al., 2010; Halme et al., 2010). Since most of the efficiency and generated energy is lost during these processes, studies on the photoanode are always focused on finding solutions to these issues.

With the rise of graphene-based materials, researchers quickly realized that the properties of the atomic thick carbon sheet (e.g., fast electron transfer and good optoelectronic properties) are promising for solving many concerns in DSSC research. For example, many studies have shown that graphene-based materials can be used as electrocatalysts in the CE to achieve outstanding performance, potentially replacing platinum-based catalysts (Roy-Mayhew et al., 2010; Choi et al., 2011a,b; Zhang et al., 2011; Zhu et al., 2011; Lin et al., 2013). These graphene-based materials include graphene oxide (GO) (Kavan et al., 2012), carbon-graphene nanocomposites (Stefik et al., 2013), CoS-graphene composites (Das et al., 2012), freeze-dried graphene (Hung and Wang, 2014), vertically-oriented graphene sheets (Yu et al., 2013), and so on. Electrolytes with graphene as conductive media also have achieved great improvement in comparison with traditional liquid electrolytes (Ahmad et al., 2011; Gun et al., 2012; Jung et al., 2012; Akhtar et al., 2013; Brennan et al., 2013; Chan et al., 2013; Neo and Ouyang, 2013; Wang and Hu, 2013; Yuan et al., 2014). Introducing graphene into photoanode designs opens up rich opportunities in DSSC research since graphene-based materials have the appropriate properties to strengthen each part of the photoanode: (i) the high visible light transparency and Young's modulus make graphene a good candidate for transparent conducting electrodes; (ii) the ultra-fast electron mobility and semi-metallic properties allow graphene to possibly serve as a charge carrier and as transfer media; and (iii) tunable bandgap and photon absorption even give graphene the potential to be a sensitizing material.
Compared with traditional DSSCs, cells with graphene photoanodes have indeed demonstrated improved performance. Meanwhile, the abundant carbon source and the simplicity of synthesizing graphene-based materials can potentially lower the cost of graphene-based DSSCs. Although the mechanisms for graphene to enhance the performance of the DSSC are yet to be fully understood, encouraging results have been obtained in applying graphene materials to DSSCs, which justifies the necessity to further investigate the use of graphene-based materials in DSSCs.

Many studies have demonstrated advantages when graphene-based materials were used in different parts of DSSCs. Nevertheless, the majority of the works have concentrated on graphene materials in the $\mathrm{CE}$ rather than in the photoanode, because of the relatively easy chemistry and fabrication of the CE. These works have been summarized in several review articles on graphene-based materials for DSSC CE (Calandra et al., 2010; Wang and Hu, 2012; Kavan et al., 2014). On the other hand, the studies on graphene-based photoanodes have been only briefly introduced in some reviews (Brennan et al., 2011; Chen et al., 2013a; Kavan et al., 2013; Macaira et al., 2013; Roy-Mayhew and Aksay, 2014). Considering the critical role of the photoanode in the DSSC, a comprehensive survey of the recent studies on graphene-based DSSC photoanodes is deemed necessary for better utilizing graphene's attractive properties and ultimately improving the performance of DSSCs.

Wehere presentan overview of the recentadvancesin the research of graphene-based materials for DSSC photoanode applications. We start the review with a brief introduction to the properties of graphene-based materials, which is useful for understanding the motivation behind the extensive exploration of graphene in various applications, particularly in DSSCs. We then discuss in detail the graphene-based materials that have been studied in the DSSC photoanode as different functioning components (i.e., transparent conducting electrode, semiconductor material, and sensitizer) and examine the reasons why the use of graphene can help improve the cell performance. In the end, we provide a perspective for the future research of graphene-based DSSC photoanodes.

\section{PROPERTIES OF GRAPHENE-BASED MATERIALS}

According to the International Union of Pure and Applied Chemistry (IUPAC), graphene is defined as "a single carbon layer of the graphite structure, describing its nature by analogy to a polycyclic aromatic hydrocarbon of quasi infinite size" (Fitzer et al., 1995). Nevertheless, the term "graphene" has been used loosely to represent not only pristine graphene but also its derivatives. The graphene-based materials we discuss here include pristine graphene, GO nanosheets, and reduced graphene oxide (rGO) nanosheets.

Although graphene-based materials are not the first carbon materials used in DSSCs, they show some outstanding and unique potential compared with other carbon materials. The earliest carbon materials used in DSSCs can be traced back to graphite-like carbon used in the CE to replace high-cost platinum, which was pioneered by Kay and Gratzel (1996). From then 
on, different types of carbon materials have been applied in DSSC applications, including fullerene and diamond-like carbon. The more recently discovered carbon nanotube (CNT) and graphene have attracted more interest, since both have mechanical strength, electrical conductivity, and thermal conductivity superior to other common materials. Nevertheless, these carbon materials are structurally related. Figure $\mathbf{2}$ is a schematic illustrating the relationships of carbon materials. Graphene (2D) can be viewed virtually as the basic modeling unit of other carbon materials since fullerene (0D), CNT (1D), and graphite (3D) can be "obtained" by wrapping, rolling, and stacking graphene sheets, respectively (Geim and Novoselov, 2007). Being limited by its dimension (i.e., $0 \mathrm{D})$, fullerene works very differently from CNT and graphene. Comparing $\mathrm{CNT}$ and graphene, their properties are similar, while CNT has slightly different chemical and electronic properties due to the high aspect ratio and strain effects. Strictly speaking, CNT and fullerene are not exactly $\mathrm{sp}^{2}$-hybridized because of strain effects. Although graphene has no significant advantage over $\mathrm{CNT}$, the mono-atomic two-dimensional $\mathrm{sp}^{2}$-hybridized carbon layer has a much larger and thinner surface, which leads to higher reactivity and transparency (Novoselov et al., 2004, 2005; Geim and Novoselov, 2007; Nair et al., 2008).

Many methods have been developed to prepare graphene, for example, mechanical exfoliation (Novoselov et al., 2004), micromechanical cleavage (Novoselov et al., 2005), graphitization of SiC (Forbeaux et al., 1998), solution exfoliation in organic solvents and surfactant solutions (Hernandez et al., 2008; Lotya et al., 2009), deposition from a gaseous precursor through chemical vapor deposition (CVD) (Kim et al., 2009a; Li et al., 2009; Kumar et al., 2010), and roll-to-roll production of films grown on copper foil (Bae et al., 2010). Among those methods, reduction of GO and CVD synthesis on metal substrates (Kim et al., 2009a; Li et al., 2009) are two most popular approaches because of their easiness, low cost and low requirements, suitability for large-scale

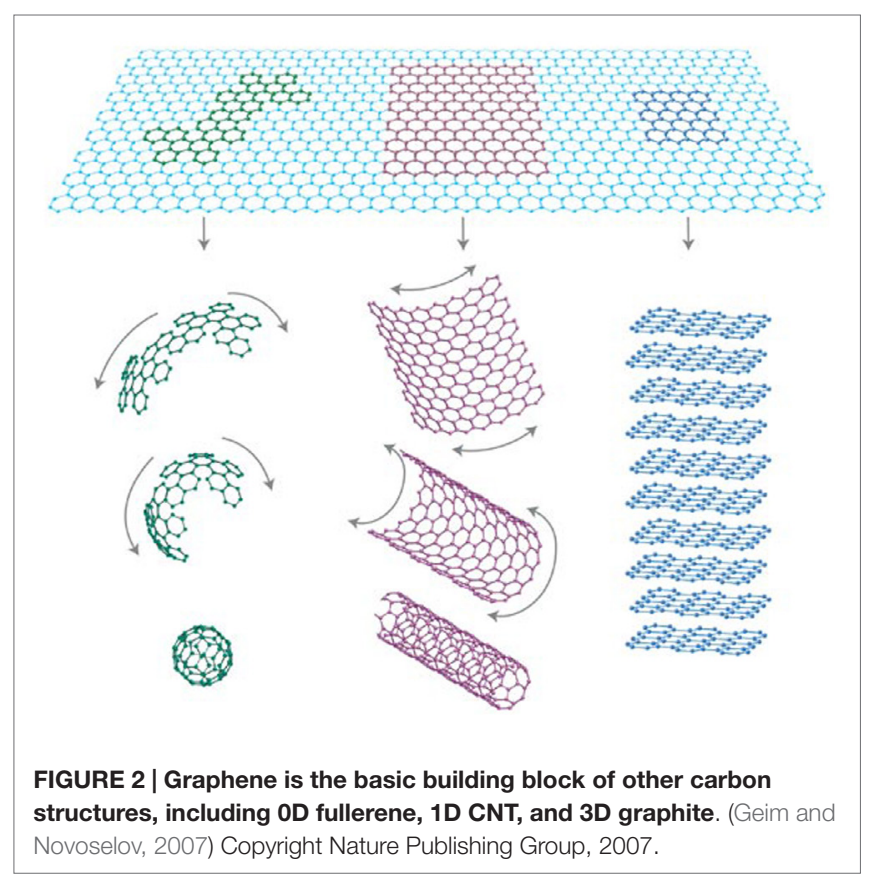

production, and accessibility by most labs. rGO is commonly synthesized in two steps: first producing GO using Hummer's method (Hummers and Offeman, 1958) or modified Hummer's methods (Stankovich et al., 2007; Dreyer et al., 2010; Lee et al., 2010; Zhu et al., 2010), and then reducing GO with reductants, such as hydrazine, to obtain rGO sheets with sizes usually in the range of $1-10 \mu \mathrm{m}$. This method is solution-processable and can produce a large amount of $\mathrm{rGO}$ sheets at one time. GO and rGO are commonly used in DSSCs, because they are graphene sheets chemically modified with functional groups and are compatible for further chemical treatments and/or fabrication processes.

One concern associated with $\mathrm{rGO}$ is that the reduction process often involves toxic chemicals and is not always environmental friendly; however, some "green" reducing agents and environmental friendly processes have been reported (Bo et al., 2014). Some aqueous processes have also been introduced to prepare large quantities of rGO (Li et al., 2008). The CVD method is a better way to produce large-scale graphene sheets with a highquality close to pristine graphene. A typical CVD process uses a carbon source, such as methane, and heats a substrate to high temperatures (such as $\sim 1000{ }^{\circ} \mathrm{C}$ ) under an $\mathrm{H}_{2}$ environment. Different substrates, such as nickel, copper, and $\mathrm{SiO}_{2}$, are used with different chemistry for the deposition of a graphene sheet (Mattevi et al., 2011). Mono-, bi-, and tri-layer graphene sheets with a desirable size can be produced by carefully choosing the synthesis conditions in a CVD process, such as time, temperature, and the type and size of a substrate (Kim et al., 2009a; Li et al., 2009). Roy-Mayhew et al. compared graphene materials prepared by CVD methods and different reducing methods in Figure 3. CVD prepared graphene has a lower oxygen content and a larger scale than $\mathrm{rGO}$ from reducing methods. The variation of properties among graphene materials requires the selection of suitable graphene materials on the basis of intended applications; for example, pristine and CVD graphene for electrodes that require high conductivity and transparency, and rGO for catalysis that demands high reactivity.

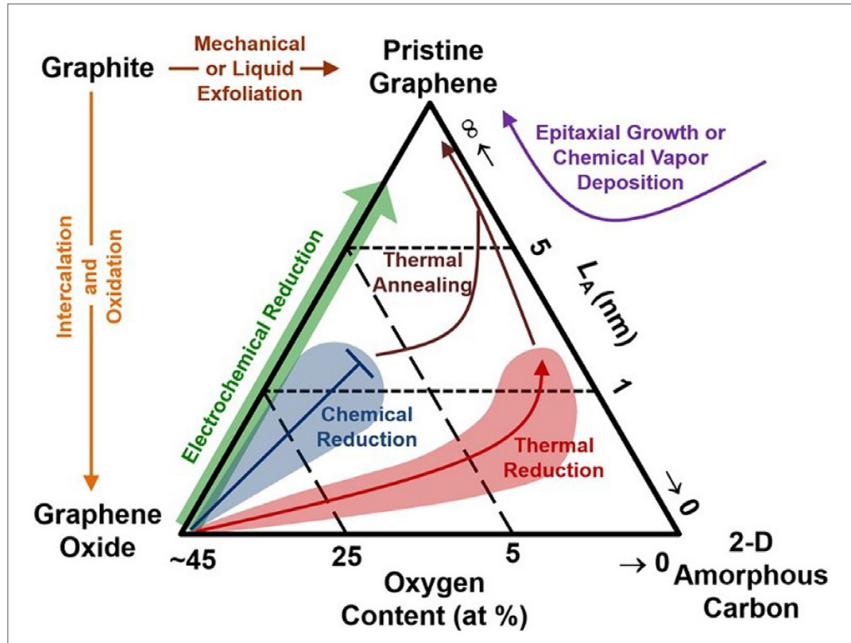

FIGURE 3 | Production of graphene materials. The triangle qualitatively represents the material space encompassed by rGOs (Roy-Mayhew, 2013). Copyright 2013 Joseph Roy-Mayhew. 
As rGO and CVD graphene bear distinct properties, they are thus adopted into DSSCs differently. Since rGO sheets are usually small in size and soluble in various solvents, coating methods, such as dip-coating and spinning coating, are used to fabricate DSSC electrodes (Hong et al., 2008; Zhang et al., 2011; Jeon and Shin, 2013). Also, because their surfaces are chemically modified, rGO sheets are used as additives to improve the electron transfer in semi-conducting material layers (Morales-Torres et al., 2012; Prakash et al., 2012). CVD synthesized graphene sheets have excellent transparency and electrical conductivity and can be directly transferred from the synthesis substrate to suitable transparent substrates and used as electrodes to collect electrons (Wang et al., 2008; Song et al., 2013; Yang et al., 2013).

The preparation method itself has a strong effect on the graphene properties. For example, intrinsic graphene is expected to have electron mobility as high as $200,000 \mathrm{~cm}^{2} / \mathrm{V} \mathrm{s}$ at room temperature (Bolotin et al., 2008; Chen et al., 2008); however, most reported values are always much lower, because various types of defects are present on graphene sheets synthesized from different methods. Holes and grain boundaries as shown in Figure $\mathbf{4}$ are common defects in a graphene sheet. These defects may affect graphene properties in many ways, from chemical and electronic properties to mechanical and optical properties, which further influences the functionality of graphene in DSSCs. For DSSCs, lower mechanical and optical properties are unfavorable for improving the performance of the transparent electrode, while defects also lead to more active carbon atoms and a larger surface area, creating opportunities for surface functionalization and decoration and, thus, improving DSSC performances. Ions introduced onto a graphene surface in many GO synthesis processes cannot be removed completely during reduction, which leads to higher surface resistivity of rGO compared with pristine graphene. The inferior conductivity of rGO may deteriorate electron transfer in the cell and/or lead to contamination of main cell components. On the bright side, surface modification on graphene sheets may change the chemical properties and enhance the reactivity of graphene sheets, which could be used to prepare high-performance hybrid material. Layer stacking is also an issue. It is challenging for most methods to provide pure monolayer graphene, and few-layer and even multilayer graphene sheets usually co-exist with monolayer ones. Multilayer graphene generally has lower transparency, although there are reports showing that more layered graphene has better conductivity (Wu et al., 2004).

Three key factors that affect the DSSC photoanode efficiency have been extensively studied: photo-electron generation, charge carrier transfer, and surface reaction and reduction. The unique and outstanding properties of graphene are ideal for addressing these factors. For instance, it has been shown that graphene has an ultrahigh theoretical surface area of $2600 \mathrm{~m}^{2} / \mathrm{g}$ and high thermoconductivity of $5 \times 10^{3} \mathrm{~W} / \mathrm{m} \mathrm{K}$. Long-range $\pi$-conjugation gives graphene exceeding electron mobility of $\sim 1500 \mathrm{~m}^{2} / \mathrm{V} \mathrm{s}$ at room temperature and a current density of $\sim 1 \times 10^{9} \mathrm{~A} / \mathrm{cm}^{2}$
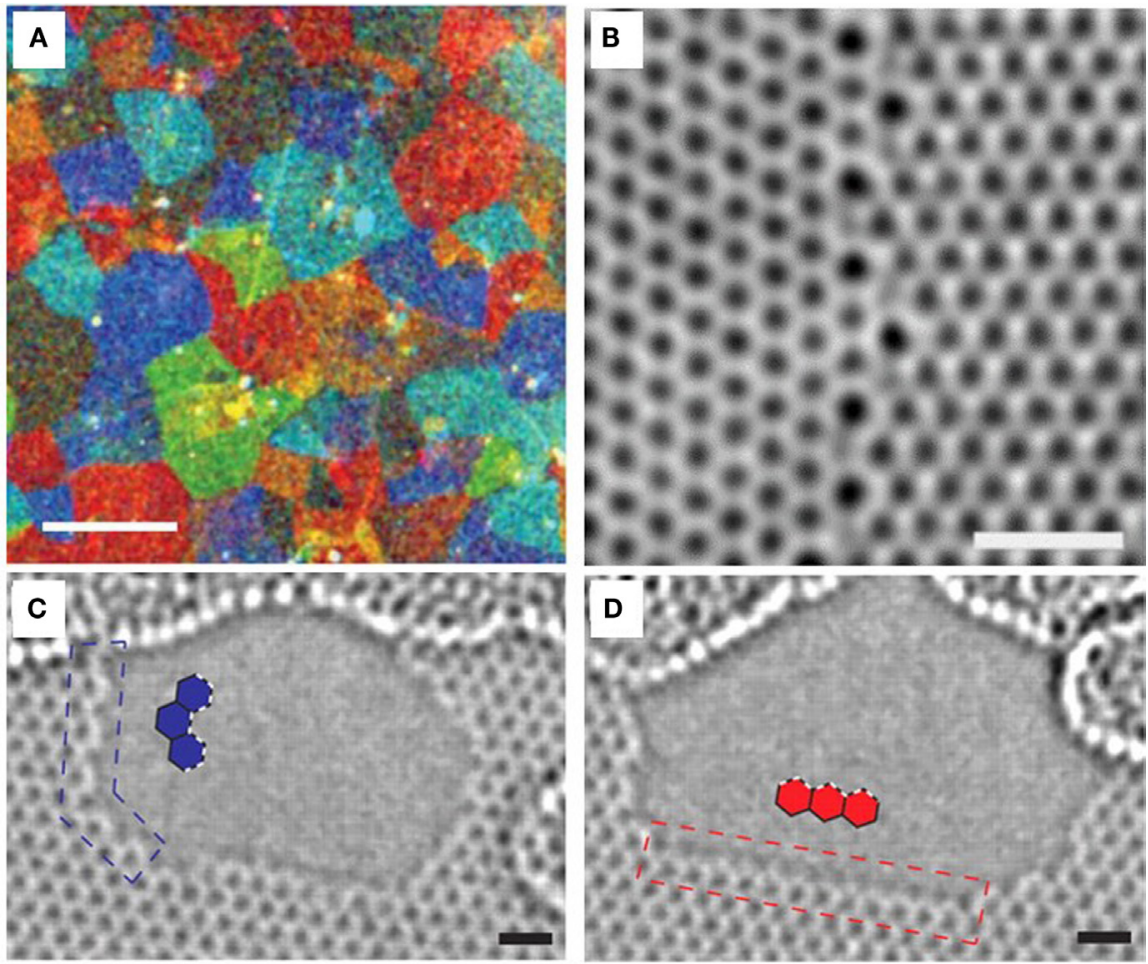

FIGURE 4 | Common defects in graphene sheets. (A) CVD-grown graphene false-color DF-TEM image; it shows grain boundaries in one graphene sheet; (Lee et al., 2013b) Copyright AAAS, 2013. (B) Aberration-corrected TEM image showing the atomic structure of graphene boundary; (Rasool et al., 2013) Copyright Nature Publication Group, 2013. (C,D) Aberration-corrected TEM images of holes on graphene sheet. (C) is armchair boundary and (D) is zigzag boundary (Girit et al., 2009). Copyright AAAS, 2009. Scale bars: (A) $3 \mu \mathrm{m}$; (B) $0.8 \mathrm{~nm}$; (C,D) $0.5 \mathrm{~nm}$. 
(Allen et al., 2010; Guldi and Sgobba, 2011; Mas-Balleste et al., 2011; Zhu et al., 2013). For perfect graphene, it absorbs $2.3 \%$ of visible light with an extinction coefficient of about $10^{8} \mathrm{~mol} /$ $\mathrm{cm}^{2}$ (Kavan et al., 2013). Although pristine graphene has a zero bandgap, the quantum confinement effect theoretically allows graphene with the structure of a nanoribbon or a quantum dot [the so-called graphene nanoribbon (GNR) and graphene quantum dot (GQD)] to have a tunable band gap covering the whole solar light spectrum. This tunability in band gap makes graphene an attractive candidate for photo-electron generator. At the same time and more obviously, graphene offers a 2D conductive support path for electron transfer with a work function of $4.42 \mathrm{eV}$, which can enhance the electron transfer in photoanode materials and reduce the electron-hole recombination rate. Additionally, the large surface area creates more occasions for reactive group decoration and enhances the chemical reaction and reduction processes. These properties from graphene meet most requirements for building a high-performance DSSC photoanode.

\section{DSSC PHOTOANODE APPLICATIONS}

\section{Transparent Conducting Electrode}

The transparent conducting electrodes (or current collectors) of a DSSC are often fabricated on a quartz substrate coated with TCOs (e.g., ITO and FTO), which have good stability, excellent electrical conductivity (sheet resistance $R_{\mathrm{s}}<10 \Omega \mathrm{sq}^{-1}$ ), and good optical transparency (>80\% for visible light) (Upadhyaya et al., 2013; Zhu et al., 2013). But the cost of TCO can be up to nearly half of the total cost of a DSSC cell (Kalyanasundaram, 2010). ITO can form a high-quality film with a smooth surface on glass but is more expensive than FTO. Additionally, the thermal stability of ITO films is limited to $350^{\circ} \mathrm{C}$, above which $\mathrm{SnO}_{2}$ crystals peel off from glass substrates (Kalyanasundaram, 2010). FTO films are more widely used in DSSCs, especially in $\mathrm{TiO}_{2}$-based DSSCs, as a high annealing temperature (e.g., $500^{\circ} \mathrm{C}$ ) is required for cell fabrication. But the surface of FTO films is reported to be uneven, and it is usually difficult to form high-quality FTO films especially on organic substrates (Hudaya et al., 2012). In addition to the fundamental requirements of mechanical integrity, conductivity, and optical transparency, research and future demand on flexible solar cells also calls for the bendability and stretchability of the cell electrodes.

Graphene has excellent electrical, optical, and mechanical properties that are attractive for making transparent conducting electrodes with a desirable performance. The high conductivity and the outstanding transparency provide graphene materials with a high potential to replace TCOs in the DSSC photoanode electrode. Graphene-based electrodes can potentially offer viable solutions to balancing the cost, surface uniformity, thermal stability, and flexibility (Nair et al., 2008; Kim et al., 2009a; Li et al., 2009).

Some calculations show that the work function of graphene is $\sim 4.42 \mathrm{eV}$, which is close to that of an FTO (4.4 eV) (Wu et al., 2004; Zhang et al., 2005; Li et al., 2009). Figure 5 compares the bandgap positions of common semiconducting materials with a calculated

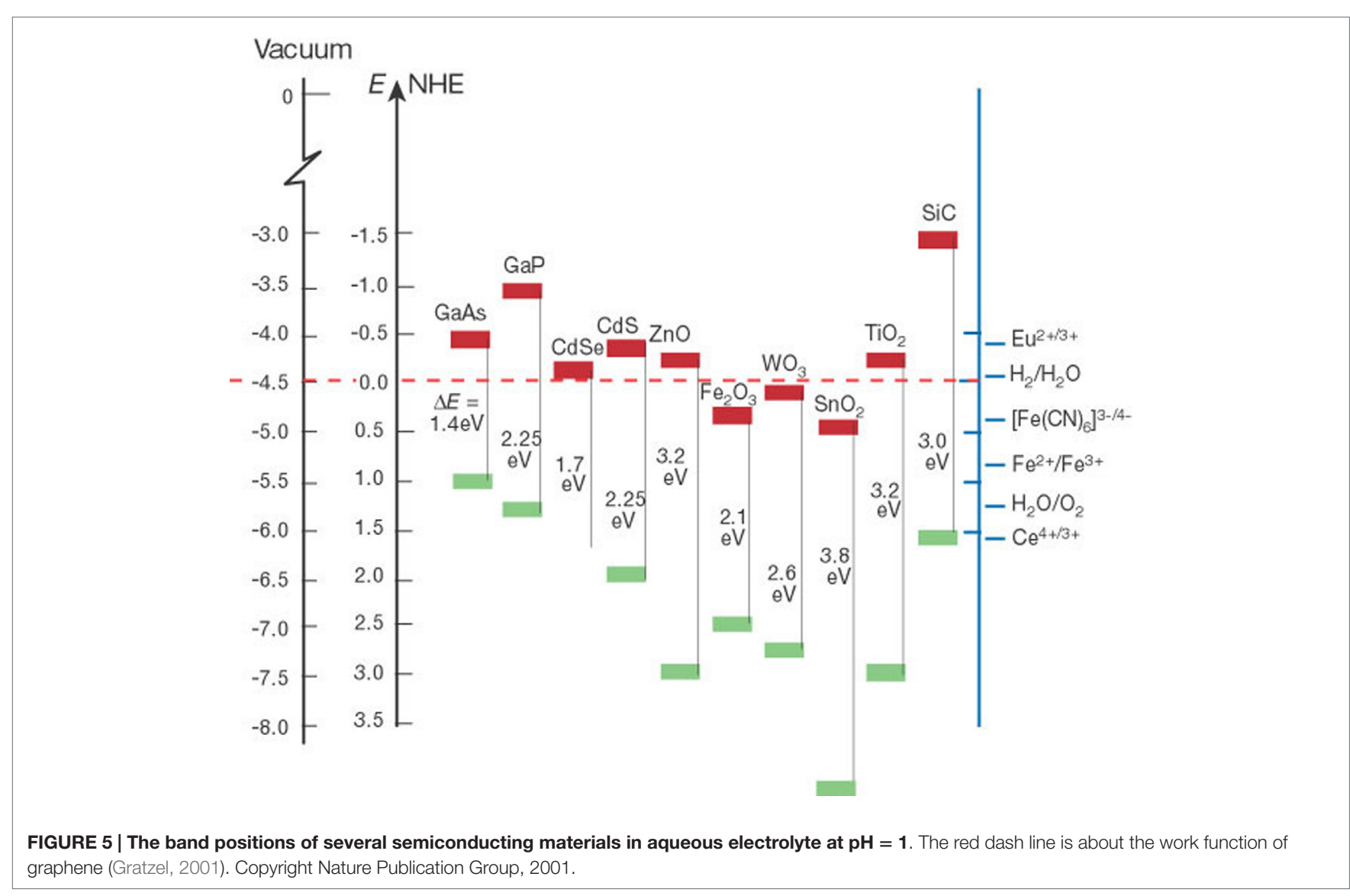


graphene work function. It can be seen that there are very small offsets between most semiconducting material conduction band edges and the work function of graphene, implying that graphene can work as a low energy loss electron shuttle to collect electrons from these semiconductors.

Muellen et al. (Wang et al., 2008) pioneered in applying graphene as a transparent conducting electrode material to the photoanode in a solid-state DSSC. By dip-coating from a hot GO solution, their graphene electrode obtained a high conductivity of $550 \mathrm{~S} \mathrm{~cm}^{-1}$ and a transparency of more than $70 \%$ over a 1000-3000 nm range. The electrode structure and transparency compared with TCOs are shown in Figure 6. The solid-state DSSC in this work had a power conversion efficiency (PCE) of $0.26 \%$, which was lower than that of the FTO-based device $(0.84 \%)$. This is mainly due to lower conductivity and optical transparency.

Most works on the current collector of the DSSC photoanode are focused on using GO or rGO. For this type of graphene electrodes, the thickness of graphene layer can be controlled by the coating process, and electrode quality is greatly affected by GO/ rGO properties and conductivities. The sheet resistance of these graphene electrodes commonly falls between 1 and $0.1 \mathrm{k} \Omega \mathrm{sq}^{-1}$, and the optical transparency at $550 \mathrm{~nm}$ is about $80 \%$ (Wu et al.,
2004; Zhang et al., 2005; Kim et al., 2009a; Li et al., 2009; Song et al., 2014). GO- or rGO-based electrodes can be easily fabricated on a large scale and can host different types of semiconducting layers. Ameen et al. prepared $\mathrm{ZnO}$ nanorods on a hot filament CVD grown GO (Ameen et al., 2012) and Farhangi et al. synthesized $\mathrm{TiO}_{2}$ nanowires on $\mathrm{GO}$ sheets in supercritical $\mathrm{CO}_{2}$ (Farhangi et al. 2012). Roh et al. further used the Langmuir-Blodgett technique to prepare rGO and modify FTO films to decrease the charge recombination at the interface of $\mathrm{TiO}_{2}$ and FTO (Roh et al., 2015).

Chemical vapor deposition provides another approach to preparing large-scale monolayer graphene sheets with a quality close to pristine graphene. Bae et al. (2010) reported the roll-to-roll production of 30-inch graphene films for transparent electrodes. Figure 7 schematically shows the roll-to-roll procedure of the graphene electrode preparation. Prior to preparing electrodes, a copper foil is rolled up and positioned in a tube furnace to synthesize graphene sheets by CVD; followed by the adhesion of polymer supports and copper etching, the graphene sheet is transferred onto a flexible polymer. The monolayer graphene electrode has resistance as low as $\sim 125 \Omega \mathrm{sq}^{-1}$ and $97.4 \%$ optical transmittance. A four-layer stacked electrode shows resistance $\sim 30 \Omega \mathrm{sq}^{-1}$ and transparency $\sim 90 \%$. These values are comparable with commercial TCO electrodes, although resistance is still high for DSSC electrodes.
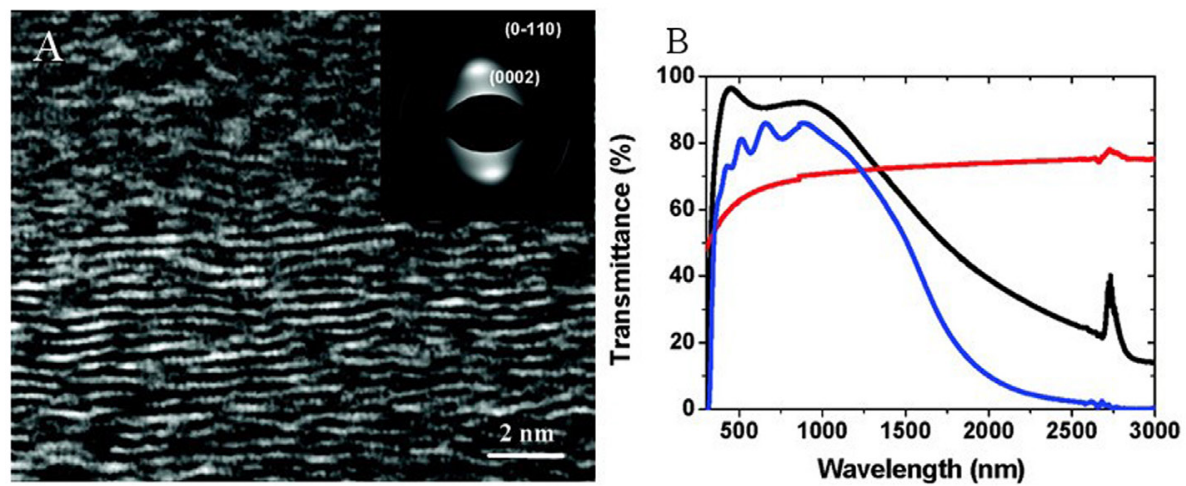

FIGURE 6 | (A) HRTEM image of graphene films with corresponding SAED pattern (inset). (B) Transmittance of a ca. 10-nm-thick graphene film (red), in comparison with that of ITO (black) and FTO (blue) (Wang et al., 2008). Copyright ACS Publications, 2008.

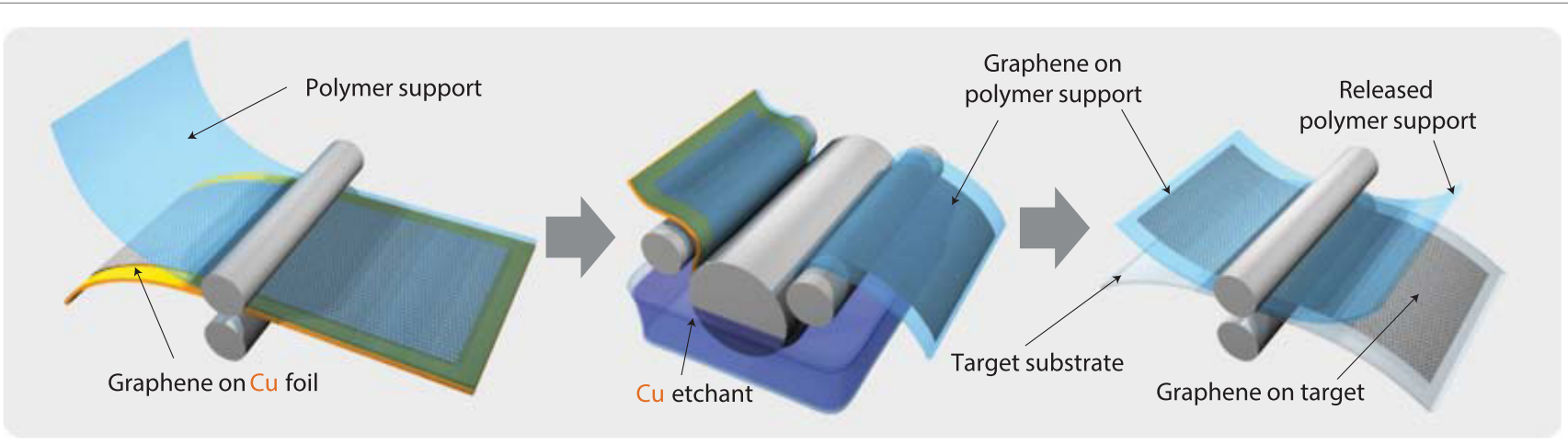

FIGURE 7 | Schematic of the roll-based production of graphene films grown on a copper foil. The process includes adhesion of polymer supports, copper etching (rinsing), and dry transfer-printing on a target substrate. A wet-chemical doping can be carried out using a setup similar to that used for etching (Bae et al., 2010). Copyright Nature Publishing Group, 2010. 
Most CVD prepared large-scale graphene sheets are grown on copper substrates and transferred to glasses by PMMA support. Selopal et al. reported DSSCs using CVD graphene in transparent conducting electrode combined with an N719 sensitizer and $\mathrm{a} \mathrm{TiO}_{2}$ semiconductor film and achieved photo-conversion efficiency as high as $2 \%$. The as-prepared photoanode transparency is higher than that of ITO- or FTO-based photoanodes; the comparison is shown in Figure 8 (Selopal et al., 2015). Dong et al. also prepared graphene-based photoanodes on metal grids as transparent conductive material, which can be used as flexible large-scale substrates (Dong et al., 2014).

As discussed before, graphene-based materials can potentially improve the transparency and reduce the surface resistance of transparent conducting electrodes. However, the transfer process of graphene sheets and the lowered mechanical strength due to defects may lead to easy cracking. Meanwhile, graphene and other carbon-based materials have been studied as high efficiency reduction catalysts and applied in CE. This catalytic reactivity may lead to a high ratio of electron waste when the graphene surface without proper coverage is exposed to the electrolyte, which is
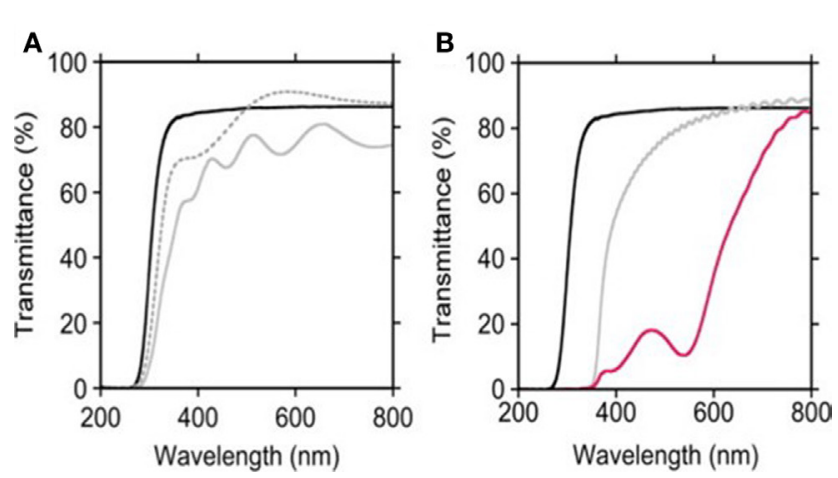

FIGURE 8 | Transmittance UV-vis spectra of photoanodes of (A) graphene (black line), ITO (gray dashed line), and FTO (gray solid line) on glass; (B) graphene on glass (black line), $\mathrm{TiO}_{2}$ on graphene (gray line), sensitized graphene- $\mathrm{TiO}_{2}$ photoanode (red line) (Selopal et al., 2015). Copyright to Elsevier 2015. undesirable for a graphene electrode solely serving as a current collector. Since it still remains a challenge to prepare high-quality graphene or graphene-based material, graphene materials have also been used as an interfacial layer to enhance electrode performance instead of fabricating graphene-only electrodes (Kim et al., 2009b).

\section{Sensitizing Material}

Graphene can serve as a sensitizing material in DSSCs since a sizeable bandgap can be opened up in graphene by quantum confinement. Indeed, as alternative to dye molecules, sensitizers based on pure graphene have been demonstrated by Yan et al. (2010). They synthesized GQDs, each of which contains a graphene moiety with 168 conjugated carbon atoms and has an absorption edge of $900 \mathrm{~nm}$. To overcome the insolubility and reduce aggregations, which are common for quantum dots, they attached flexible long chains of 1,3,5-trialkyl phenyl moieties to the edge of the GQD as shown in Figure 9A. They used GQDs for the sensitization of $\mathrm{TiO}_{2}$ in a regular DSSC. As shown in Figure 9B, the DSSC exhibited an open circuit voltage of $0.48 \mathrm{~V}$ and a fill factor of 0.58 , while the short circuit current was only $0.2 \mathrm{~mA} \mathrm{~cm}^{-2}$.

So far, GQDs alone as sensitizers have not achieved high efficiency; however, as a co-sensitizer, GQDs can significantly improve the performance of common dyes. Typically, GQDs are prepared either using "bottom-up" synthesis from organic molecules or "top-down" cutting from various carbon sources (e.g., breaking GO sheets into small pieces). Zhu et al. (2015) and Lee et al. (2013a) fabricated GQDs by simply oxidizing herringbone-type carbon nanofibers and analyzed the photoluminescence behavior of GQDs mixed with N719 dye at different ratios. As shown in Figure 10A, GQDs possess an upconversion PL property. The upconversion emission band remains at around $525 \mathrm{~nm}$, while the excitation wavelength changes from 600 to $750 \mathrm{~nm}$. The GODs improve dye performance at different dye concentration and light wavelength, as compared in Figures 10B-D. This upconversion ability transfers longer wavelength photon energy to the center of highest efficiency of dye molecules and further improves the efficiency. The PCE was reported to enhance from 7.28 to $7.95 \%$.
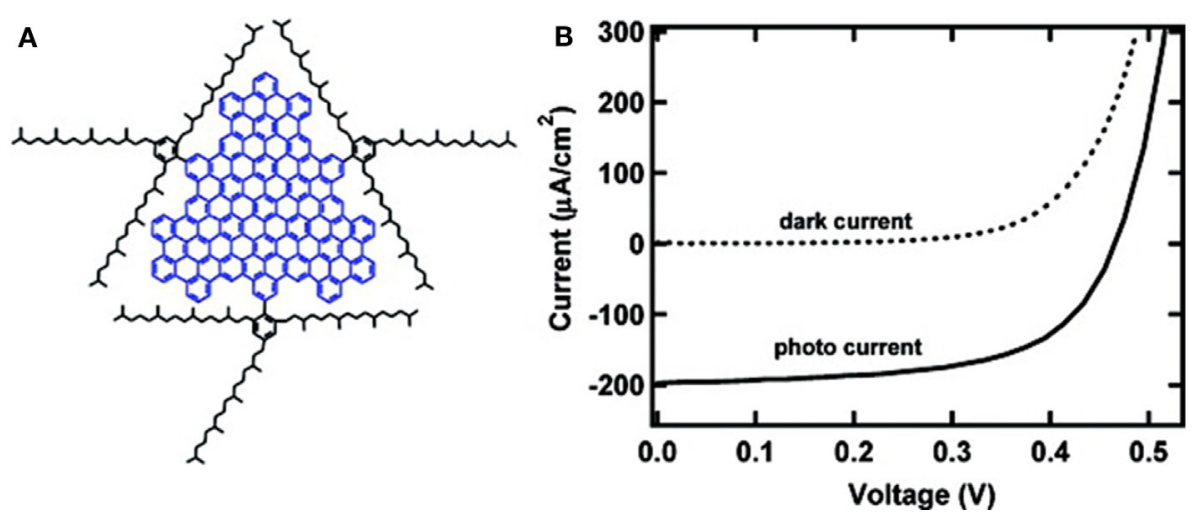

FIGURE 9 | (A) Molecular structure of GQD. The graphene moiety is marked blue and the three solubilizing groups are black. (B) The current-voltage characteristics in the dark and under illumination, respectively (Yan et al., 2010). Copyright ACS Publications, 2010. 

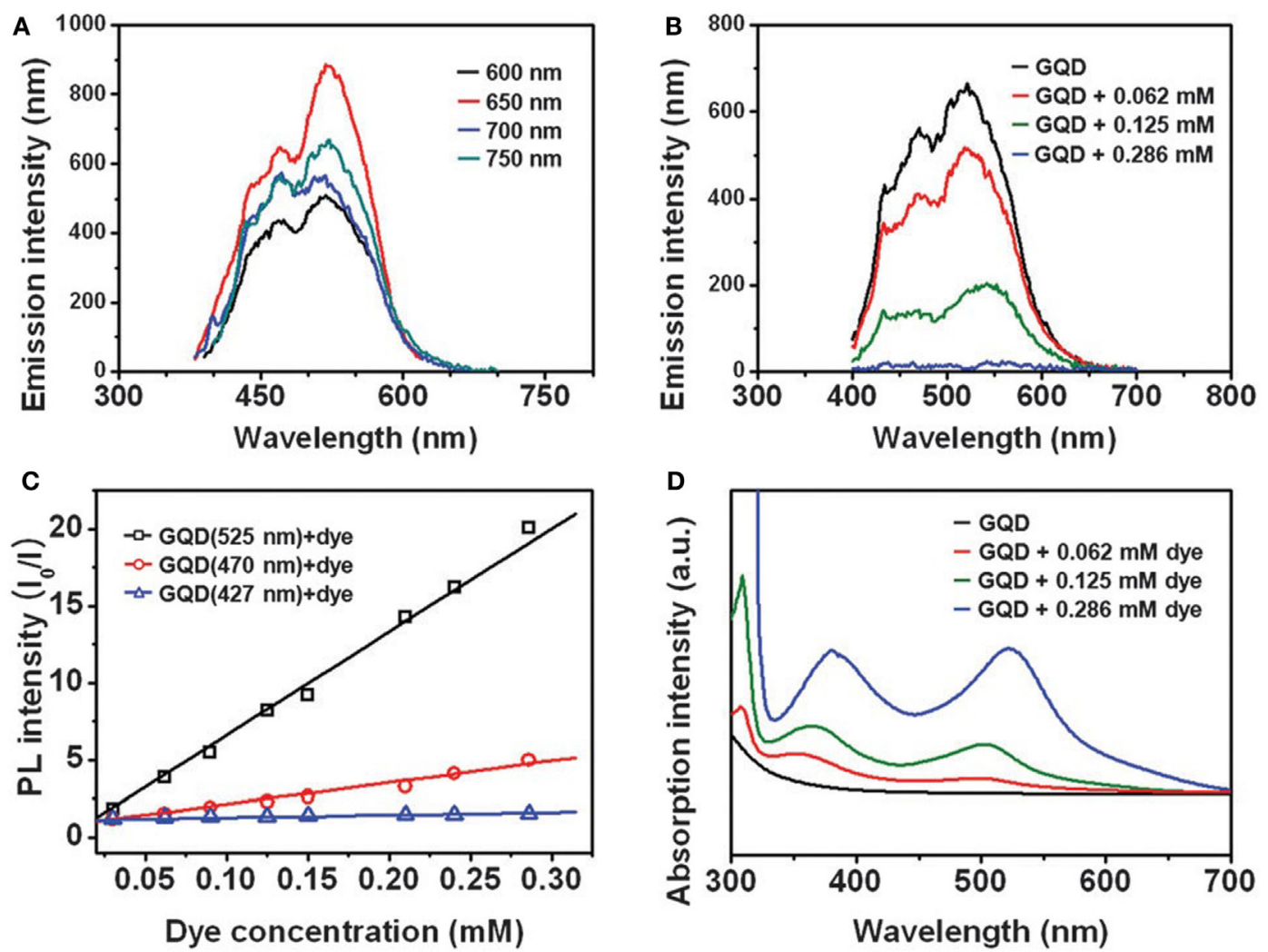

FIGURE 10 | (A) Upconverted PL spectra of the GQDs at different excitation wavelengths. (B) Fluorescence spectra of GQDs as a function of the amount of dye molecules from 62 to $286 \mu \mathrm{M}$. (C) Stern-Volmer plots of the fluorescence quenching of GQDs with the N719 dye. (D) Absorption spectra of GQDs as a function of the amount of dye molecules from 62 to $286 \mu \mathrm{M}$ (Lee et al., 2013a). Copyright RSC Publishing, 2013.

Different co-sensitizing approaches have been studied by many groups. Gupta et al. (2011) and Routh et al. (2013) both studied GQDs combined with polymers. Routh et al. synthesized GQDs using a sono-Fenton reaction to break GO into small pieces in an aqueous environment and further fabricated composites with a water-soluble polymer. The efficiency was enhanced from 1.76 to $2.09 \%$. Fang et al. prepared GQDs in different sizes to optimize the DSSC performance and obtained efficiency improvement from 5.1 to $6.1 \%$ (Fang et al., 2014). Mihalache et al. recently explored GQDs as co-sensitizers with standard N3 dye and found that GDQs could enhance the charge separation and reduce recombination and transfer energy to N3 dye molecules (Mihalache et al., 2015).

\section{Photoanode Additive}

Although it is still challenging to mass produce high-quality graphene at low cost, researchers can add a small number of graphene sheets as additives to semiconducting materials to enhance the electron transfer process in the photoanode. Similar works have been widely tested on CNTs and resulted in around 100\% current increasing (Kongkanand et al., 2007; Yang et al., 2010). Without carbon material support, electrons that are injected into $\mathrm{TiO}_{2}$ nanoparticles or other nanostructures may transfer around and need a much longer transfer distance. As shown in Figure 11,
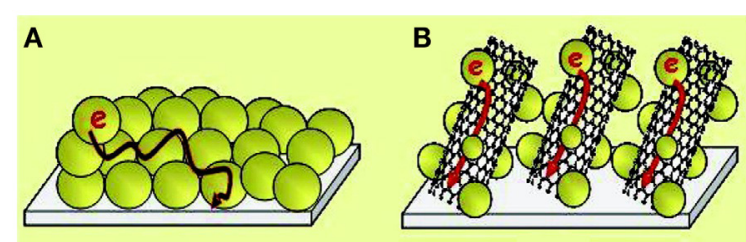

FIGURE 11 | Electron transport through pure $\mathrm{TiO}_{2}$ nanoparticles (A) versus across CNTs (B). (Kongkanand et al., 2007) Copyright ACS Publications, 2007.

a CNT provides a faster electron transfer path and significantly reduces the electron-hole recombination rate in the $\mathrm{TiO}_{2}$ material layer. Compared with CNTs in Figure 12, graphene nanosheets create a much larger surface area to anchor $\mathrm{TiO}_{2}$ nanoparticles, and the photo-induced electrons can be captured and transferred in a more efficient way.

Yang et al. (2010) reported that the short circuit current improved from 3.35 to $11.26 \mathrm{~mA} / \mathrm{cm}^{2}$ and total efficiency from 0.58 to $5.01 \%$ by introducing graphene additives into the $\mathrm{TiO}_{2}$ photoanode of DSSCs. After synthesizing and reducing $\mathrm{GO}$ sheets, the $\mathrm{rGO}$ sheets ranged from 0.2 to $2 \mu \mathrm{m}$ in size 


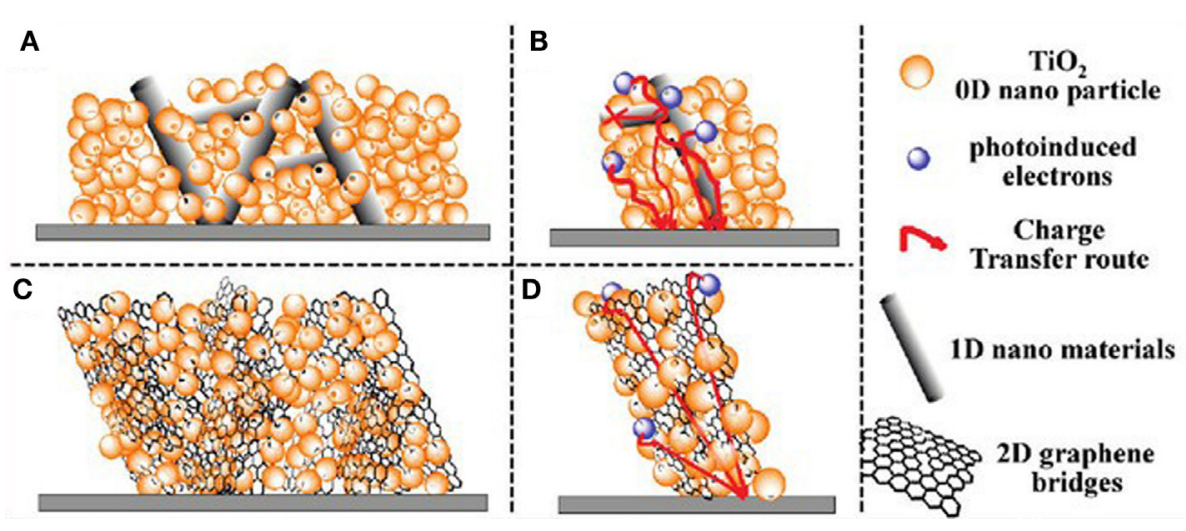

FIGURE 12 | Comparison of material loading and electron transport across CNT (A,C) and through graphene sheets (B,D) (Yang et al., 2010). Copyright ACS Publications, 2010.

TABLE 1 | Comparison of graphene as photoanode additives.

\begin{tabular}{|c|c|c|c|c|c|c|c|}
\hline \multirow[t]{2}{*}{ Reference } & \multirow[t]{2}{*}{ Graphene added cell } & \multirow[t]{2}{*}{ Preparation method } & \multirow[t]{2}{*}{ Reference cell } & \multicolumn{2}{|c|}{ Graphene hybrid cell } & \multicolumn{2}{|c|}{ Reference cell } \\
\hline & & & & $I_{\mathrm{sc}}\left(\mathrm{mA} / \mathrm{cm}^{2}\right)$ & $\eta(\%)$ & $I_{\mathrm{sc}}\left(\mathrm{mA} / \mathrm{cm}^{2}\right)$ & $\eta(\%)$ \\
\hline Sun et al. (2010) & $\begin{array}{l}\text { Nafion-coated graphene with } \\
\mathrm{TiO}_{2} \text { P25 }\end{array}$ & Heterogeneous coagulation & $\mathrm{TiO}_{2} \mathrm{P} 25$ & 8.38 & 4.28 & 5.04 & 2.70 \\
\hline Tang et al. (2010) & Graphene (from GO) with $\mathrm{TiO}_{2}$ & Molecular grafting & $\mathrm{TiO}_{2}$ & 6.67 & 1.68 & 1.95 & 0.32 \\
\hline Yang et al. (2010) & Graphene (from GO) with $\mathrm{TiO}_{2}$ & Solution dispersion & CNT with $\mathrm{TiO}_{2}$ & 16.29 & 6.97 & 3.35 & 0.58 \\
\hline He et al. (2011) & $\begin{array}{l}\text { Graphene (from GO) with } \mathrm{TiO}_{2} \\
\text { P25 }\end{array}$ & Solvothermal approach & $\mathrm{TiO}_{2} \mathrm{P} 25$ & $13.5^{\mathrm{a}}$ & $7.25^{\mathrm{a}}$ & 6.20 & 2.85 \\
\hline Yang et al. (2011b) & Graphene (from GO) with $\mathrm{NiO}$ & $\mathrm{NiO}$ Solution dispersion & $\mathrm{NiO}$ & 0.27 & 0.0094 & 0.14 & 0.0034 \\
\hline Yen et al. (2011) & $\begin{array}{l}\text { Graphene (from GO) and } \\
\text { MWCNTs hybrid with } \mathrm{TiO}_{2}\end{array}$ & Solution based dispersion & Pristine $\mathrm{TiO}_{2}$ & 11.27 & 6.11 & 8.61 & 4.54 \\
\hline Madhavan et al. (2012) & $\begin{array}{l}\text { Graphene (from GO) with } \mathrm{TiO}_{2} \\
\text { nanofiber }\end{array}$ & Electrospinning & $\mathrm{TiO}_{2}$ fiber & 16.2 & 7.6 & 13.9 & 6.3 \\
\hline Fan et al. (2012) & $\begin{array}{l}\text { Graphene (from GO) with } \mathrm{TiO}_{2} \\
\text { nanosheets }\end{array}$ & Solution based dispersion & $\mathrm{TiO}_{2}$ nanosheet & 16.8 & 5.77 & 13.7 & 4.61 \\
\hline Chatterjee et al. (2013) & PHET with grafted rGO (from GO) & Molecular grafting & $\mathrm{TiO}_{2}$ & 7.5 & 3.06 & 5.6 & 2.66 \\
\hline Chen et al. (2013b) & Graphene (from GO) with $\mathrm{TiO}_{2}$ & $\begin{array}{l}\text { In situ simultaneous } \\
\text { reduction-hydrolysis technique }\end{array}$ & $\mathrm{TiO}_{2}$ & 13.93 & 7.1 & 10.99 & 5.3 \\
\hline Kim et al. (2013) & $\begin{array}{l}\text { Graphene-embedded 3D } \mathrm{TiO}_{2} \\
\text { inverse opal electrodes }\end{array}$ & Infiltrated into the templates & $\begin{array}{l}\text { Pure } \mathrm{TiO}_{2} \text { inverse } \\
\text { opal electrode }\end{array}$ & 17.10 & 7.52 & 12.39 & 4.86 \\
\hline Madhavan et al. (2013) & $\begin{array}{l}\mathrm{TiO}_{2} \text {-ZnO-graphene } \\
\text { nanocomposite fibers }\end{array}$ & Electro-spinning & $\begin{array}{l}\mathrm{TiO}_{2}-\mathrm{ZnO} \\
\text { nanocomposite } \\
\text { fiber }\end{array}$ & 9.4 & 3.7 & 6.3 & 2.7 \\
\hline $\begin{array}{l}\text { Shanmugam et al. } \\
\text { (2013) }\end{array}$ & $\begin{array}{l}\text { Multilayer oxygenated graphene } \\
\text { with } \mathrm{TiO}_{2}\end{array}$ & $\begin{array}{l}\text { CVD then chemical } \\
\text { modification }\end{array}$ & $\mathrm{TiO}_{2}$ & 16.0 & 6.7 & 12.7 & 5.6 \\
\hline Sharma et al. (2013) & $\begin{array}{l}\text { Graphene modified } \mathrm{TiO}_{2} \text { with } \\
\text { modified dyes }\end{array}$ & Solution based dispersion & $\begin{array}{l}\mathrm{TiO}_{2} \text { with modified } \\
\text { dyes }\end{array}$ & 16.69 & 8.15 & 16.18 & 7.35 \\
\hline
\end{tabular}

aThree different types of composites are compared in this paper. Data are from the best one, i.e., ultra-small $2 \mathrm{~nm} \mathrm{TiO}_{2}$-graphene nanosheets.

(about $1 \mu \mathrm{m}$ on average). By dispersing $\mathrm{TiO}_{2} \mathrm{P} 25$ into polymersupported graphene water/ethanol solutions, $\mathrm{TiO}_{2}$ suspension was prepared for the photoanode formation. Different methods have been developed to improve the compatibility between graphene and semiconducting materials. Tang et al. (2010) reported the use of large-area rGO sheets with $\mathrm{TiO}_{2}$ on ITO through 
molecular drafting. The GO sheets that were synthesized using Hummer's method were pretreated with titanium butoxide before being reduced by hydrolysis. After electrophoretic deposition, the prepared photoanodes were soaked in traditional dye N719. The photoanode had better conductivity than a pure $\mathrm{TiO}_{2}$ structure, and the cell exhibited a short circuit current of $6.67 \mathrm{~mA} \mathrm{~cm}^{-2}$, an open circuit voltage of $0.56 \mathrm{~V}$, and a fill factor of 0.45 . The PCE of the cell was $1.68 \%$. Anish et al. (Madhavan et al., 2012) combined graphene with $\mathrm{TiO}_{2}$ nanofibers to increase the surface area and reported a short circuit current of $16.2 \mathrm{~mA} \mathrm{~cm}^{-2}$, an open circuit voltage of $0.71 \mathrm{~V}$, a fill factor of 0.66 , and an efficiency of $7.6 \%$, compared with pure $\mathrm{TiO}_{2}$ nanofibers at $13.9 \mathrm{~mA} \mathrm{~cm}^{-2}, 0.71 \mathrm{~V}, 0.63$, and $6.3 \%$, respectively. Semiconducting materials in other structures have also been investigated for the integration of graphene materials, such as $\mathrm{TiO}_{2}$ nanosheets (Fan et al., 2012), TiOx interlayer (Yang et al., 2011a), NiO/graphene composites (Yang et al., 2011b), ZnO nanorods-graphene hybrid structures (Qurashi, 2015), and so on. Some published works are summarized and compared in Table 1.

Bell et al. (2011) and Wang et al. (2012) studied the promoting effects of rGO and graphene additives, respectively. Wang's work clearly showed that the electron lifetime decreased from 17.6 to $6.4 \mathrm{~ms}$ by adding graphene, and $\sim 0.7 \mathrm{wt} \%$ graphene addition led to the highest efficiency. When the graphene ratio is lower than $0.7 \mathrm{wt} \%$, more graphene can further improve the electron transfer process; however, when the graphene is over $0.7 \mathrm{wt} \%$, more graphene in contact with $\mathrm{TiO}_{2}$ may create more chances for recombination. He et al. (2013) and Zhang et al. (2014) also investigated the $\mathrm{TiO}_{2}$ particle size effects and the layer thickness effects on electron mobility in graphene- $\mathrm{TiO}_{2}$ composites. In He's work, as shown by c-AFM dark current images and nano $I-V$ curves, when the $\mathrm{TiO}_{2}$ particle size decreases, a more continuous electron transport network is formed, resulting in a higher electron mobility in the smaller-sized $\mathrm{TiO}_{2}$-based composite electrode.

\section{CONCLUSION AND PERSPECTIVE}

Compared with the massive studies on graphene-based materials in the CE of the DSSC, the depth and the width of research on employing graphene in the DSSC photoanode needs to be significantly extended, presenting rich opportunities to the researchers involved in the areas of graphene materials and DSSCs. On the one hand, the DSSC photoanode is related to more complex photochemical processes, which can be greatly affected by quantum hall effects and other properties of graphene sheets. Since the properties of graphene-based materials are highly dependent on the sizes, thickness, and surface conditions, the controllable synthesis of graphene materials with tunable morphology and adjustable properties is highly desirable but still challenging. On the other hand, while some graphene-based materials, such as $\mathrm{GO}$ and rGO, are good reduction catalysts for the CE, they may lead to high reduction reaction rate that can cause a huge loss of efficiency when used in the photoanode. However, many studies have already shown that graphene materials with appropriate structural, physical, and chemical properties can play important roles in solving many issues limiting the performance of DSSC photoanodes, either as an electron collection and transfer medium or as a photon absorption and sensitizing material. Further study on graphene can bring novel and better options to fabricating better DSSC photoanodes.

For graphene transparent conducting electrodes, the unsatisfactory transparency is mainly caused by multiple-layer graphene stacking and the high sheet resistance due to surface defects and oxidization. Better processing procedures are necessary to overcome these problems and enhance the chance for graphene to be used as feasible alternatives to TCOs in the DSSC photoanode. The strength and flexibility of graphene outperforms other flexible candidates. Further modification of graphene nanosheets may create a new generation of flexible electrodes. Considerable progress has been made on the preparation of graphene transparent conducting electrodes at the laboratory level; however, it remains a challenge to costeffectively produce high-quality graphene on an industrial scale for the practical use of graphene in transparent conducting electrodes (Bonaccorso et al., 2015).

As a sensitizer in DSSCs, intrinsic graphene has a much lower efficiency than dyes or semiconductor quantum dots. But GQDs with better quality and size control can be a sensitizer potentially covering the whole visible light spectrum. GQDs can also be a great enhancement to the current photo-sensitizing structure, as well as an enhancement to all photoelectron-chemistry. As an additive in the semiconducting layer in the photoanode, pure graphene has been demonstrated to be a good option. Further modification to graphene sheets may bring more enhanced activity, and bandgap modification may reduce the current electrolyte reduction problem.

As a shining star, graphene, the newly found 2D material, already brings brand new opportunities, and it may further improve the DSSC photoanode, reduce the DSSC cost, and set a new record of energy conversion efficiency in solar energy applications. Meanwhile, the studies on graphene-based materials for DSSC photoanodes can be transformative to similar devices/ systems. For example, perovskite solar cells (PSCs) have recently drawn a lot of attention; (Service, 2014) since the structures of the PSC are similar to that of the DSSC, lessons learned from using graphene materials in DSSCs may be extended to PSC cell designs, fast tracking the development of this new type of solar cells.

\section{AUTHOR CONTRIBUTIONS}

XG did the review, performed the analysis, and wrote the manuscript. GL performed editing and gave suggestions on review objective and manuscript outline. JC initiated the study, performed editing, and gave guidelines on the review objective.

\section{ACKNOWLEDGMENTS}

JC acknowledges the financial support from the US National Science Foundation (EECS-1001039 and IIP-1128158) and Research Growth Initiative Program of UWM. GL thanks UAA for a Faculty Development Grant for financial support. 


\section{REFERENCES}

Ahmad, I., Khan, U., and Gun'ko, Y. K. (2011). Graphene, carbon nanotube and ionic liquid mixtures: towards new quasi-solid state electrolytes for dye sensitised solar cells. J. Mater. Chem. 21, 16990-16996. doi:10.1039/ cljm11537e

Ahmad, S., Guillen, E., Kavan, L., Gratzel, M., and Nazeeruddin, M. K. (2013). Metal free sensitizer and catalyst for dye sensitized solar cells. Energy Environ. Sci. 6, 3439-3466. doi:10.1039/c3ee41888j

Akhtar, M. S., Kwon, S., Stadler, F. J., and Yang, O. B. (2013). High efficiency solid state dye sensitized solar cells with graphene-polyethylene oxide composite electrolytes. Nanoscale 5, 5403-5411. doi:10.1039/c3nr00390f

Allen, M. J., Tung, V. C., and Kaner, R. B. (2010). Honeycomb carbon: a review of graphene. Chem. Rev. 110, 132-145. doi:10.1021/cr900070d

Ameen, S., Akhtar, M. S., Song, M., and Shin, H. S. (2012). Vertically aligned ZnO nanorods on hot filament chemical vapor deposition grown graphene oxide thin film substrate: solar energy conversion. ACS Appl. Mater. Interfaces 4, 4405-4412. doi:10.1021/am301064j

Anjusree, G. S., Nair, A. S., Nair, S. V., and Vadukumpully, S. (2013). One-pot hydrothermal synthesis of $\mathrm{TiO} 2 /$ graphene nanocomposites for enhanced visible light photocatalysis and photovoltaics. RSC Adv. 3, 12933-12938. doi:10.1039/ c3ra41388h

Bae, S., Kim, H., Lee, Y., Xu, X., Park, J. S., Zheng, Y., et al. (2010). Roll-to-roll production of 30-inch graphene films for transparent electrodes. Nat. Nanotechnol. 5, 574-578. doi:10.1038/nnano.2010.132

Bell, N. J., Yun, H. N., Du, A. J., Coster, H., Smith, S. C., and Amal, R. (2011). Understanding the enhancement in photoelectrochemical properties of photocatalytically prepared TiO2-reduced graphene oxide composite. J. Phys. Chem. C 115, 6004-6009. doi:10.1021/jp1113575

Bo, Z., Shuai, X., Mao, S., Yang, H., Qian, J., Chen, J., et al. (2014). Green preparation of reduced graphene oxide for sensing and energy storage applications. Sci. Rep. 4, 4684. doi:10.1038/srep04684

Bolotin, K. I., Sikes, K. J., Jiang, Z., Klima, M., Fudenberg, G., Hone, J., et al. (2008). Ultrahigh electron mobility in suspended graphene. Solid State Commun. 146, 351-355. doi:10.1016/j.ssc.2008.02.024

Bonaccorso, F., Colombo, L., Yu, G., Stoller, M., Tozzini, V., Ferrari, A. C., et al. (2015). Graphene, related two-dimensional crystals, and hybrid systems for energy conversion and storage. Science 347, 6217. doi:10.1126/ science. 1246501

Brennan, L. J., Barwich, S. T., Satti, A., Faure, A., and Gun'ko, Y. K. (2013). Graphene-ionic liquid electrolytes for dye sensitised solar cells. J. Mater. Chem. A 1, 8379-8384. doi:10.1039/c3ta11609c

Brennan, L. J., Byrne, M. T., Bari, M., and Gun'ko, Y. K. (2011). Carbon nanomaterials for dye-sensitized solar cell applications: a bright future. Adv. Energy Mater. 1, 472-485. doi:10.1002/aenm.201100136

Burschka, J., Pellet, N., Moon, S. J., Humphry-Baker, R., Gao, P., Nazeeruddin, M. K., et al. (2013). Sequential deposition as a route to high-performance perovskite-sensitized solar cells. Nature 499, 316-319. doi:10.1038/nature12340

Calandra, P., Calogero, G., Sinopoli, A., and Gucciardi, P. G. (2010). Metal nanoparticles and carbon-based nanostructures as advanced materials for cathode application in dye-sensitized solar cells. Int. J. Photoenergy 2010, 109495. doi:10.1155/2010/109495

Chan, Y. F., Wang, C. C., and Chen, C. Y. (2013). Quasi-solid DSSC based on a gel-state electrolyte of PAN with 2-D graphenes incorporated. J. Mater. Chem. A 1, 5479-5486. doi:10.1039/c3ta01684f

Chatterjee, S., Patra, A. K., Bhaumik, A., and Nandi, A. K. (2013). Poly[3-(2hydroxyethyl)-2,5-thienylene] grafted reduced graphene oxide: an efficient alternate material of $\mathrm{TiO} 2$ in dye sensitized solar cells. Chem. Commun. (Camb) 49, 4646-4648. doi:10.1039/c3cc40843d

Chen, D., Zhang, H., Liu, Y., and Li, J. H. (2013a). Graphene and its derivatives for the development of solar cells, photoelectrochemical, and photocatalytic applications. Energy Environ. Sci. 6, 1362-1387. doi:10.1039/c3ee23586f

Chen, L., Zhou, Y., Tu, W., Li, Z., Bao, C., Dai, H., et al. (2013b). Enhanced photovoltaic performance of a dye-sensitized solar cell using graphene-TiO2 photoanode prepared by a novel in situ simultaneous reduction-hydrolysis technique. Nanoscale 5, 3481-3485. doi:10.1039/c3nr34059g
Chen, J. H., Jang, C., Xiao, S., Ishigami, M., and Fuhrer, M. S. (2008). Intrinsic and extrinsic performance limits of graphene devices on $\mathrm{SiO} 2$. Nat. Nanotechnol. 3, 206-209. doi:10.1038/nnano.2008.58

Choi, H., Kim, H., Hwang, S., Choi, W., and Jeon, M. (2011a). Dye-sensitized solar cells using graphene-based carbon nano composite as counter electrode. Sol. Energy Mater. Sol. Cells 95, 323-325. doi:10.1016/j.solmat.2010.04.044

Choi, H., Kim, H., Hwang, S., Han, Y., and Jeon, M. (2011b). Graphene counter electrodes for dye-sensitized solar cells prepared by electrophoretic deposition. J. Mater. Chem. 21, 7548-7551. doi:10.1039/c1jm11145k

Chu, S., and Majumdar, A. (2012). Opportunities and challenges for a sustainable energy future. Nature 488, 294-303. doi:10.1038/nature11475

Chung, I., Lee, B., He, J., Chang, R. P., and Kanatzidis, M. G. (2012). All-solid-state dye-sensitized solar cells with high efficiency. Nature 485, 486-489. doi:10.1038/ nature11067

Das, S., Sudhagar, P., Nagarajan, S., Ito, E., Lee, S. Y., Kang, Y. S., et al. (2012). Synthesis of graphene-CoS electro-catalytic electrodes for dye sensitized solar cells. Carbon N. Y. 50, 4815-4821. doi:10.1016/j.carbon.2012.06.006

Dong, P., Zhu, Y., Zhang, J., Peng, C., Yan, Z., Li, L., et al. (2014). Graphene on metal grids as the transparent conductive material for dye sensitized solar cell. J. Phys. Chem. C 118, 25863-25868. doi:10.1021/jp505735j

Dreyer, D. R., Park, S., Bielawski, C. W., and Ruoff, R. S. (2010). The chemistry of graphene oxide. Chem. Soc. Rev. 39, 228-240. doi:10.1039/b917103g

Etgar, L., Gao, P., Xue, Z., Peng, Q., Chandiran, A. K., Liu, B., et al. (2012). Mesoscopic CH3NH3PbI3/TiO2 heterojunction solar cells. J. Am. Chem. Soc. 134, 17396-17399. doi:10.1021/ja307789s

Fan, J. J., Liu, S. W., and Yu, J. G. (2012). Enhanced photovoltaic performance of dye-sensitized solar cells based on $\mathrm{TiO} 2$ nanosheets/graphene composite films. J. Mater. Chem. 22, 17027-17036. doi:10.1039/c2jm33104g

Fang, X. L., Li, M. Y., Guo, K. M., Li, J., Pan, M. C., Bai, L. H., et al. (2014). Graphene quantum dots optimization of dye-sensitized solar cells. Electrochim. Acta 137, 634-638. doi:10.1016/j.electacta.2014.06.075

Farhangi, N., Medina-Gonzalez, Y., Chowdhury, R. R., and Charpentier, P. A. (2012). Growing $\mathrm{TiO} 2$ nanowires on the surface of graphene sheets in supercritical CO2: characterization and photoefficiency. Nanotechnology 23, 294005. doi:10.1088/0957-4484/23/29/294005

Fitzer, E., Kochling, K. H., Boehm, H. P., and Marsh, H. (1995). Recommended terminology for the description of carbon as a solid - (Iupac recommendations 1995). Pure Appl. Chem. 67, 473-506. doi:10.1351/pac199567030473

Forbeaux, I., Themlin, J. M., and Debever, J. M. (1998). Heteroepitaxial graphite on $6 \mathrm{H}-\mathrm{SiC}(0001)$ : interface formation through conduction-band electronic structure. Phys. Rev. B 58, 16396-16406. doi:10.1103/PhysRevB.58.16396

Geim, A. K., and Novoselov, K. S. (2007). The rise of graphene. Nat. Mater. 6, 183-191. doi:10.1038/nmat1849

Girit, C. O., Meyer, J. C., Erni, R., Rossell, M. D., Kisielowski, C., Yang, L., et al. (2009). Graphene at the edge: stability and dynamics. Science 323, 1705-1708. doi:10.1126/science.1166999

Goetzberger, A., Hebling, C., and Schock, H. W. (2003). Photovoltaic materials, history, status and outlook. Mater. Sci. Eng. R Rep. 40, 1-46. doi:10.1016/ S0927-796x (02)00092-X

Gratzel, M. (2001). Photoelectrochemical cells. Nature 414, 338-344. doi:10.1038/35104607

Gratzel, M. (2009). Recent advances in sensitized mesoscopic solar cells. Acc. Chem. Res. 42, 1788-1798. doi:10.1021/ar900141y

Green, M. A. (2001). Third generation photovoltaics: ultra-high conversion efficiency at low cost. Prog. Photovolt. 9, 123-135. doi:10.1002/pip.360

Guldi, D. M., and Sgobba, V. (2011). Carbon nanostructures for solar energy conversion schemes. Chem. Commun. (Camb) 47, 606-610. doi:10.1039/ c0cc02411b

Gun, J., Kulkarni, S. A., Xiu, W., Batabyal, S. K., Sladkevich, S., Prikhodchenko, P. V., et al. (2012). Graphene oxide organogel electrolyte for quasi solid dye sensitized solar cells. Electrochem. commun. 19, 108-110. doi:10.1016/j. elecom.2012.03.025

Gupta, V., Chaudhary, N., Srivastava, R., Sharma, G. D., Bhardwaj, R., and Chand, S. (2011). Luminscent graphene quantum dots for organic photovoltaic devices. J. Am. Chem. Soc. 133, 9960-9963. doi:10.1021/ja2036749

Hagfeldt, A., Boschloo, G., Sun, L., Kloo, L., and Pettersson, H. (2010). Dyesensitized solar cells. Chem. Rev. 110, 6595-6663. doi:10.1021/cr900356p 
Halme, J., Vahermaa, P., Miettunen, K., and Lund, P. (2010). Device physics of dye solar cells. Adv. Mater. 22, E210-E234. doi:10.1002/adma.201000726

Haynes, H., Shinde, M., Nuraje, N., Subbaiyan, N. K., D’Souza, F., and Asmatulu, R. (2011). "Experimental screen printing alternatives for the production of multi-layer dye sensitized solar cells," in Int. SAMPE Tech. Conf, Vol. 43, Fort Worth, TX: Society for the Advancement of Material and Process Engineering (SAMPE) 14.

He, Z., Guai, G., Liu, J., Guo, C., Loo, J. S., Li, C. M., et al. (2011). Nanostructure control of graphene-composited $\mathrm{TiO} 2$ by a one-step solvothermal approach for high performance dye-sensitized solar cells. Nanoscale 3, 4613-4616. doi:10.1039/clnr11300c

He, Z., Phan, H., Liu, J., Nguyen, T.-Q., and Tan, T. T. Y. (2013). Understanding $\mathrm{TiO} 2$ size-dependent electron transport properties of a graphene- $\mathrm{TiO} 2$ photoanode in dye-sensitized solar cells using conducting atomic force microscopy. Adv. Mater. 25, 6900-6904. doi:10.1002/adma.201303327

Hernandez, Y., Nicolosi, V., Lotya, M., Blighe, F. M., Sun, Z., De, S., et al. (2008). High-yield production of graphene by liquid-phase exfoliation of graphite. Nat. Nanotechnol. 3, 563-568. doi:10.1038/nnano.2008.215

Hong, W. J., Xu, Y. X., Lu, G. W., Li, C., and Shi, G. Q. (2008). Transparent graphene/ PEDOT-PSS composite films as counter electrodes of dye-sensitized solar cells. Electrochem. commun. 10, 1555-1558. doi:10.1016/j.elecom.2008.08.007

Hudaya, C., Park, J. H., and Lee, J. K. (2012). Effects of process parameters on sheet resistance uniformity of fluorine-doped tin oxide thin films. Nanoscale Res. Lett. 7, 17. doi:10.1186/1556-276X-7-17

Hummers, W. S., and Offeman, R. E. (1958). Preparation of graphitic oxide. J. Am. Chem. Soc. 80, 1339-1339. doi:10.1021/ja01539a017

Hung, K. H., and Wang, H. W. (2014). A freeze-dried graphene counter electrode enhances the performance of dye-sensitized solar cells. Thin Solid Films 550, 515-520. doi:10.1016/j.tsf.2013.10.129

Jayawardena, K. D., Rozanski, L. J., Mills, C. A., Beliatis, M. J., Nismy, N. A., and Silva, S. R. (2013). 'Inorganics-in-organics': recent developments and outlook for $4 \mathrm{G}$ polymer solar cells. Nanoscale 5, 8411-8427. doi:10.1039/c3nr02733c

Jeon, N. J., Noh, J. H., Yang, W. S., Kim, Y. C., Ryu, S., Seo, J., et al. (2015). Compositional engineering of perovskite materials for high-performance solar cells. Nature 517, 476-480. doi:10.1038/nature14133

Jeon, Y. S., and Shin, H. S. (2013). Working Electrode for Dye Sensitized Solar Cell, Dye Sensitized Solar Cell with the Working Electrode, and Its Manufacturing Method. Korea Patent KR2013033083A.

Jung, M. H., Kang, M. G., and Chu, M. J. (2012). Iodide-functionalized graphene electrolyte for highly efficient dye-sensitized solar cells. J. Mater. Chem. 22, 16477-16483. doi:10.1039/c2jm33028h

Kalyanasundaram, K. (2010). Dye-Sensitized Solar Cells. Lausanne, Switzerland: EPFL press.

Kavan, L., Yum, J. H., and Graetzel, M. (2012). Optically transparent cathode for $\mathrm{Co}(\mathrm{III} / \mathrm{II})$ mediated dye-sensitized solar cells based on graphene oxide. ACS Appl. Mater. Interfaces 4, 6999-7006. doi:10.1021/am302253e

Kavan, L., Yum, J. H., and Graetzel, M. (2013). Application of graphene-based nanostructures in dye-sensitized solar cells. Phys. Status Solidi B Basic Solid State Phys. 250, 2643-2648. doi:10.1002/pssb.201300064

Kavan, L., Yum, J. H., and Graetzel, M. (2014). Graphene-based cathodes for liquid-junction dye sensitized solar cells: electrocatalytic and mass transport effects. Electrochim. Acta 128, 349-359. doi:10.1016/j.electacta.2013.08.112

Kay, A., and Gratzel, M. (1996). Low cost photovoltaic modules based on dye sensitized nanocrystalline titanium dioxide and carbon powder. Sol. Energy Mater. Sol. Cells 44, 99-117. doi:10.1016/0927-0248(96)00063-3

Kim, H. N., Yoo, H., and Moon, J. H. (2013). Graphene-embedded 3D TiO2 inverse opal electrodes for highly efficient dye-sensitized solar cells: morphological characteristics and photocurrent enhancement. Nanoscale 5, 4200-4204. doi:10.1039/c3nr33672g

Kim, K. S., Zhao, Y., Jang, H., Lee, S. Y., Kim, J. M., Kim, K. S., et al. (2009a). Largescale pattern growth of graphene films for stretchable transparent electrodes. Nature 457, 706-710. doi:10.1038/nature07719

Kim, S. R., Parvez, M. K., and Chhowalla, M. (2009b). UV-reduction of graphene oxide and its application as an interfacial layer to reduce the back-transport reactions in dye-sensitized solar cells. Chem. Phys. Lett. 483, 124-127. doi:10.1016/j.cplett.2009.10.066

Kojima, A., Teshima, K., Shirai, Y., and Miyasaka, T. (2009). Organometal halide perovskites as visible-light sensitizers for photovoltaic cells. J. Am. Chem. Soc. 131, 6050-6051. doi:10.1021/ja809598r
Kongkanand, A., Dominguez, R. M., and Kamat, P. V. (2007). Single wall carbon nanotube scaffolds for photoelectrochemical solar cells. Capture and transport of photogenerated electrons. Nano Lett. 7, 676-680. doi:10.1021/nl0627238

Kumar, S., McEvoy, N., Lutz, T., Keeley, G. P., Nicolosi, V., Murray, C. P., et al. (2010). Gas phase controlled deposition of high quality large-area graphene films. Chem. Commun. (Camb) 46, 1422-1424. doi:10.1039/b919725g

Lee, E., Ryu, J., and Jang, J. (2013a). Fabrication of graphene quantum dots via size-selective precipitation and their application in upconversion-based DSSCs. Chem. Commun. (Camb) 49, 9995-9997. doi:10.1039/c3cc45588b

Lee, G. H., Cooper, R. C., An, S. J., Lee, S., van der Zande, A., Petrone, N., et al. (2013b). High-strength chemical-vapor-deposited graphene and grain boundaries. Science 340, 1073-1076. doi:10.1126/science.1235126

Lee, S. H., Kim, H. W., Hwang, J. O., Lee, W. J., Kwon, J., Bielawski, C. W., et al. (2010). Three-dimensional self-assembly of graphene oxide platelets into mechanically flexible macroporous carbon films. Angew. Chem. Int. Ed. Engl. 49, 10084-10088. doi:10.1002/anie.201006240

Li, D., Muller, M. B., Gilje, S., Kaner, R. B., and Wallace, G. G. (2008). Processable aqueous dispersions of graphene nanosheets. Nat. Nanotechnol. 3, 101-105. doi:10.1038/nnano.2007.451

Li, X., Cai, W., An, J., Kim, S., Nah, J., Yang, D., et al. (2009). Large-area synthesis of high-quality and uniform graphene films on copper foils. Science 324, 1312-1314. doi:10.1126/science. 1171245

Lin, J. Y., Chan, C. Y., and Chou, S. W. (2013). Electrophoretic deposition of transparent MoS2-graphene nanosheet composite films as counter electrodes in dye-sensitized solar cells. Chem. Commun. (Camb) 49, 1440-1442. doi:10.1039/ c2cc38658e

Lotya, M., Hernandez, Y., King, P. J., Smith, R. J., Nicolosi, V., Karlsson, L. S., et al. (2009). Liquid phase production of graphene by exfoliation of graphite in surfactant/water solutions. J. Am. Chem. Soc. 131, 3611-3620. doi:10.1021/ ja807449u

Macaira, J., Andrade, L., and Mendes, A. (2013). Review on nanostructured photoelectrodes for next generation dye-sensitized solar cells. Renew. Sustain. Energ. Rev. 27, 334-349. doi:10.1016/j.rser.2013.07.011

Madhavan, A. A., Kalluri, S., Chacko, D. K., Arun, T. A., Nagarajan, S., Subramanian, K. R. V., et al. (2012). Electrical and optical properties of electrospun TiO2graphene composite nanofibers and its application as DSSC photo-anodes. RSC Adv. 2, 13032-13037. doi:10.1039/c2ra22091a

Madhavan, A. A., Mohandas, A., Licciulli, A., Sanosh, K. P., Praveen, P., Jayakumar, R., et al. (2013). Electrospun continuous nanofibers based on a TiO2-ZnOgraphene composite. RSC Adv. 3, 25312-25316. doi:10.1039/c3ra44574g

Mas-Balleste, R., Gomez-Navarro, C., Gomez-Herrero, J., and Zamora, F. (2011). 2D materials: to graphene and beyond. Nanoscale 3, 20-30. doi:10.1039/ c0nr00323a

Mattevi, C., Kim, H., and Chhowalla, M. (2011). A review of chemical vapour deposition of graphene on copper. J. Mater. Chem. 21, 3324-3334. doi:10.1039/ c0jm02126a

Mihalache, I., Radoi, A., Mihaila, M., Munteanu, C., Marin, A., Danila, M., et al. (2015). Charge and energy transfer interplay in hybrid sensitized solar cells mediated by graphene quantum dots. Electrochim. Acta 153, 306-315. doi:10.1016/j.electacta.2014.11.200

Morales-Torres, S., Pastrana-Martinez, L. M., Figueiredo, J. L., Faria, J. L., and Silva, A. M. (2012). Design of graphene-based TiO2 photocatalysts - a review. Environ. Sci. Pollut. Res. Int. 19, 3676-3687. doi:10.1007/s11356-012-0939-4

Nair, R. R., Blake, P., Grigorenko, A. N., Novoselov, K. S., Booth, T. J., Stauber, T., et al. (2008). Fine structure constant defines visual transparency of graphene. Science 320, 1308. doi:10.1126/science. 1156965

Nazeeruddin, M. K., Baranoff, E., and Gratzel, M. (2011). Dye-sensitized solar cells: a brief overview. Sol. Energy 85, 1172-1178. doi:10.1016/j.solener.2011.01.018

Nazeeruddin, M. K., Zakeeruddin, S. M., Humphry-Baker, R., Jirousek, M., Liska, P., Vlachopoulos, N., et al. (1999). Acid-base equilibria of (2,2'-bipyridyl-4,4'-dicarboxylic acid)ruthenium(II) complexes and the effect of protonation on charge-transfer sensitization of nanocrystalline titania. Inorg. Chem. 38, 6298-6305. doi:10.1021/ic990916a

Neo, C. Y., and Ouyang, J. Y. (2013). The production of organogels using graphene oxide as the gelator for use in high-performance quasi-solid state dye-sensitized solar cells. Carbon N. Y. 54, 48-57. doi:10.1016/j.carbon.2012.11.002

Novoselov, K. S., Geim, A. K., Morozov, S. V., Jiang, D., Zhang, Y., Dubonos, S. V., et al. (2004). Electric field effect in atomically thin carbon films. Science 306, 666-669. doi:10.1126/science.1102896 
Novoselov, K. S., Jiang, D., Schedin, F., Booth, T. J., Khotkevich, V. V., Morozov, S. V., et al. (2005). Two-dimensional atomic crystals. Proc. Natl. Acad. Sci. U.S.A. 102, 10451-10453. doi:10.1073/pnas.0502848102

Prakash, S. K., Singh, H., Panjiar, H., Manhas, S., and Daniel, B. S. S. (2012). Application of graphene oxide and $\mathrm{TiO}_{2}$ in the fabrication of dye sensitized solar cells module by electrode modification. Adv. Mater. Res. 585, 255-259. doi:10.4028/www.scientific.net/AMR.585.255

Qurashi, A., Subrahmanyam, K. S., and Kumar, P. (2015). Nanofiller graphene-ZnO hybrid nanoarchitecture: optical, electrical and optoelectronic investigation. J. Mater. Chem. C 3, 11959-11964. doi:10.1039/C5TC02729B

Rasool, H. I., Ophus, C., Klug, W. S., Zettl, A., and Gimzewski, J. K. (2013). Measurement of the intrinsic strength of crystalline and polycrystalline graphene. Nat. Commun. 4, 2811. doi:10.1038/ncomms3811

Roh, K. M., Jo, E. H., Chang, H., Han, T. H., and Jang, H. D. (2015). High performance dye-sensitized solar cells using graphene modified fluorine-doped tin oxide glass by Langmuir-Blodgett technique. J. Solid State Chem. 224, 71-75. doi:10.1016/j.jssc.2014.04.022

Routh, P., Das, S., Shit, A., Bairi, P., Das, P., and Nandi, A. K. (2013). Graphene quantum dots from a facile sono-Fenton reaction and its hybrid with a polythiophene graft copolymer toward photovoltaic application. ACS Appl. Mater. Interfaces 5, 12672-12680. doi:10.1021/am4040174

Roy-Mayhew, J. D. (2013). Functionalized Graphene Sheets in Dye-Sensitized Solar Cell Counter Electrodes. Ph.D. Thesis, Princeton University, Princeton, NJ.

Roy-Mayhew, J. D., and Aksay, I. A. (2014). Graphene materials and their use in dye-sensitized solar cells. Chem. Rev. 114, 6323-6348. doi:10.1021/ cr400412a

Roy-Mayhew, J. D., Bozym, D. J., Punckt, C., and Aksay, I. A. (2010). Functionalized graphene as a catalytic counter electrode in dye-sensitized solar cells. ACS Nano 4, 6203-6211. doi:10.1021/nn1016428

Selopal, G. S., Milan, R., Ortolani, L., Morandi, V., Rizzoli, R., Sberveglieri, G., et al. (2015). Graphene as transparent front contact for dye sensitized solar cells. Sol. Energy Mater. Sol. Cells 135, 99-105. doi:10.1016/j.solmat.2014.10.016

Service, R. F. (2014). Energy technology. Perovskite solar cells keep on surging. Science 344, 458. doi:10.1126/science.344.6183.458

Shanmugam, M., Durcan, C., Gedrim, R. J., Bansal, T., and Yu, B. (2013). Oxygenated-graphene-enabled recombination barrier layer for high performance dye-sensitized solar cell. Carbon N. Y. 60, 523-530. doi:10.1016/j. carbon.2013.04.083

Sharma, G. D., Daphnomili, D., Gupta, K. S. V., Gayathri, T., Singh, S. P., Angaridis, P. A., et al. (2013). Enhancement of power conversion efficiency of dye-sensitized solar cells by co-sensitization of zinc-porphyrin and thiocyanate-free ruthenium(II)-terpyridine dyes and graphene modified TiO2 photoanode. RSC Adv. 3, 22412-22420. doi:10.1039/c3ra42537a

Song, J., Yin, Z., Yang, Z., Amaladass, P., Wu, S., Ye, J., et al. (2011). Enhancement of photogenerated electron transport in dye-sensitized solar cells with introduction of a reduced graphene oxide-TiO2 junction. Chemistry 17, 10832-10837. doi:10.1002/chem.201101263

Song, M., Ameen, S., Akhtar, M. S., Seo, H. K., and Shin, H. S. (2013). HFCVD grown graphene like carbon-nickel nanocomposite thin film as effective counter electrode for dye sensitized solar cells. Mater. Res. Bull. 48, 4538-4543. doi:10.1016/j.materresbull.2013.07.045

Song, M., Seo, H. K., Ameen, S., Akhtar, M. S., and Shin, H. S. (2014). Low resistance transparent graphene-like carbon thin film substrates for high performance dye sensitized solar cells. Electrochim. Acta 115, 559-565. doi:10.1016/j. electacta.2013.10.216

Stankovich, S., Dikin, D. A., Piner, R. D., Kohlhaas, K. A., Kleinhammes, A., Jia, Y., et al. (2007). Synthesis of graphene-based nanosheets via chemical reduction of exfoliated graphite oxide. Carbon N. Y. 45, 1558-1565. doi:10.1016/j. carbon.2007.02.034

Stefik, M., Yum, J. H., Hu, Y. L., and Gratzel, M. (2013). Carbon-graphene nanocomposite cathodes for improved $\mathrm{Co}(\mathrm{II} / \mathrm{III})$ mediated dye-sensitized solar cells. J. Mater. Chem. A 1, 4982-4987. doi:10.1039/c3ta01635h

Sun, S. R., Gao, L., and Liu, Y. Q. (2010). Enhanced dye-sensitized solar cell using graphene-TiO2 photoanode prepared by heterogeneous coagulation. Appl. Phys. Lett. 96, 083113. doi:10.1063/1.3318466

Tang, B., and Hu, G. X. (2012). Two kinds of graphene-based composites for photoanode applying in dye-sensitized solar cell. J. Power Sources 220, 95-102. doi:10.1016/j.jpowsour.2012.07.093
Tang, B., Hu, G. X., Gao, H. Y., and Shi, Z. X. (2013). Three-dimensional graphene network assisted high performance dye sensitized solar cells. J. Power Sources 234, 60-68. doi:10.1016/j.jpowsour.2013.01.130

Tang, Y. B., Lee, C. S., Xu, J., Liu, Z. T., Chen, Z. H., He, Z., et al. (2010). Incorporation of graphenes in nanostructured $\mathrm{TiO}(2)$ films via molecular grafting for dye-sensitized solar cell application. ACS Nano 4, 3482-3488. doi:10.1021/nn100449w

Upadhyaya, H. M., Senthilarasu, S., Hsu, M. H., and Kumar, D. K. (2013). Recent progress and the status of dye-sensitised solar cell (DSSC) technology with state-of-the-art conversion efficiencies. Sol. Energy Mater. Sol. Cells 119, 291-295. doi:10.1016/j.solmat.2013.08.031

Wang, H., and Hu, Y. H. (2012). Graphene as a counter electrode material for dye-sensitized solar cells. Energy Environ. Sci. 5, 8182-8188. doi:10.1039/ c2ee21905k

Wang, H., and Hu, Y. H. (2013). Electrolyte-induced precipitation of graphene oxide in its aqueous solution. J. Colloid Interface Sci. 391, 21-27. doi:10.1016/j. jcis.2012.09.056

Wang, H., Leonard, S. L., and Hu, Y. H. (2012). Promoting effect of graphene on dye-sensitized solar cells. Ind. Eng. Chem. Res. 51, 10613-10620. doi:10.1021/ ie $300563 \mathrm{~h}$

Wang, M., Anghel, A. M., Marsan, B., Cevey Ha, N. L., Pootrakulchote, N., Zakeeruddin, S. M., et al. (2009). CoS supersedes Pt as efficient electrocatalyst for triiodide reduction in dye-sensitized solar cells. J. Am. Chem. Soc. 131, 15976-15977. doi:10.1021/ja905970y

Wang, M., Chamberland, N., Breau, L., Moser, J. E., Humphry-Baker, R., Marsan, B., et al. (2010). An organic redox electrolyte to rival triiodide/iodide in dye-sensitized solar cells. Nat. Chem. 2, 385-389. doi:10.1038/nchem.610

Wang, X., Zhi, L., and Mullen, K. (2008). Transparent, conductive graphene electrodes for dye-sensitized solar cells. Nano Lett. 8, 323-327. doi:10.1021/ nl072838r

Wu, Z., Chen, Z., Du, X., Logan, J. M., Sippel, J., Nikolou, M., et al. (2004). Transparent, conductive carbon nanotube films. Science 305, 1273-1276. doi:10.1126/science. 1101243

Xu, F., Chen, J., Wu, X., Zhang, Y., Wang, Y. X., Sun, J., et al. (2013). Graphene scaffolds enhanced photogenerated electron transport in $\mathrm{ZnO}$ photoanodes for high-efficiency dye-sensitized solar cells. J. Phys. Chem. C 117, 8619-8627. doi:10.1021/jp312379b

Yan, X., Cui, X., Li, B., and Li, L. S. (2010). Large, solution-processable graphene quantum dots as light absorbers for photovoltaics. Nano Lett. 10, 1869-1873. doi:10.1021/nl101060h

Yang, C. Y., Bi, H., Wan, D. Y., Huang, F. Q., Xie, X. M., and Jiang, M. H. (2013). Direct PECVD growth of vertically erected graphene walls on dielectric substrates as excellent multifunctional electrodes. J. Mater. Chem. A 1, 770-775. doi:10.1039/c2ta00234e

Yang, H., Guo, C., Guai, G. H., Song, Q., Jiang, S. P., and Li, C. M. (2011a). Reduction of charge recombination by an amorphous titanium oxide interlayer in layered graphene/quantum dots photochemical cells. ACS Appl. Mater. Interfaces 3, 1940-1945. doi:10.1021/am200154h

Yang, H. B., Guai, G. H., Guo, C. X., Song, Q. L., Jiang, S. P., Wang, Y. L., et al. (2011b). NiO/graphene composite for enhanced charge separation and collection in p-type dye sensitized solar cell. J. Phys. Chem. C 115, 12209-12215. doi:10.1021/jp201178a

Yang, J., Ganesan, P., Teuscher, J., Moehl, T., Kim, Y. J., Yi, C., et al. (2014). Influence of the donor size in D-pi-A organic dyes for dye-sensitized solar cells. J. Am. Chem. Soc. 136, 5722-5730. doi:10.1021/ja500280r

Yang, N., Zhai, J., Wang, D., Chen, Y., and Jiang, L. (2010). Two-dimensional graphene bridges enhanced photoinduced charge transport in dye-sensitized solar cells. ACS Nano 4, 887-894. doi:10.1021/nn901660v

Yen, M. Y., Hsiao, M. C., Liao, S. H., Liu, P. I., Tsai, H. M., Ma, C. C. M., et al. (2011). Preparation of graphene/multi-walled carbon nanotube hybrid and its use as photoanodes of dye-sensitized solar cells. Carbon N. Y. 49, 3597-3606. doi:10.1016/j.carbon.2011.04.062

Yu, K. H., Wen, Z. H., Pu, H. H., Lu, G. H., Bo, Z., Kim, H., et al. (2013). Hierarchical vertically oriented graphene as a catalytic counter electrode in dye-sensitized solar cells. J. Mater. Chem. A 1, 188-193. doi:10.1039/c2ta00380e

Yuan, S. S., Tang, Q. W., Hu, B. B., Ma, C. Q., Duan, J. L., and He, B. L. (2014). Efficient quasi-solid-state dye-sensitized solar cells from graphene incorporated conducting gel electrolytes. J. Mater. Chem. A 2, 2814-2821. doi:10.1039/ c3ta14385f 
Zhang, D. W., Li, X. D., Li, H. B., Chen, S., Sun, Z., Yin, X. J., et al. (2011). Graphene-based counter electrode for dye-sensitized solar cells. Carbon N. Y. 49, 5382-5388. doi:10.1016/j.carbon.2011.08.005

Zhang, H. Y., Wang, W. G., Liu, H., Wang, R., Chen, Y. M., and Wang, Z. W. (2014). Effects of TiO2 film thickness on photovoltaic properties of dye-sensitized solar cell and its enhanced performance by graphene combination. Mater. Res. Bull. 49, 126-131. doi:10.1016/j.materresbull.2013.08.058

Zhang, M., Fang, S., Zakhidov, A. A., Lee, S. B., Aliev, A. E., Williams, C. D., et al. (2005). Strong, transparent, multifunctional, carbon nanotube sheets. Science 309, 1215-1219. doi:10.1126/science.1115311

Zhang, Z. P., Ito, S., O’Regan, B., Kuang, D. B., Zakeeruddin, S. M., Liska, P., et al. (2007). The electronic role of the TiO2 light-scattering layer in dye-sensitized solar cells. Z. Phys. Chem. 221, 319-327. doi:10.1524/ zpch.2007.221.3.319

Zhou, H., Chen, Q., Li, G., Luo, S., Song, T. B., Duan, H. S., et al. (2014). Photovoltaics. Interface engineering of highly efficient perovskite solar cells. Science 345, 542-546. doi:10.1126/science.1254050

Zhu, G., Pan, L. K., Lu, T., Xu, T., and Sun, Z. (2011). Electrophoretic deposition of reduced graphene-carbon nanotubes composite films as counter electrodes of dye-sensitized solar cells. J. Mater. Chem. 21, 14869-14875. doi:10.1039/ cljm12433a
Zhu, J. H., Chen, M. J., He, Q. L., Shao, L., Wei, S. Y., and Guo, Z. H. (2013). An overview of the engineered graphene nanostructures and nanocomposites. RSC Adv. 3, 22790-22824. doi:10.1039/c3ra44621b

Zhu, S. J., Song, Y. B., Zhao, X. H., Shao, J. R., Zhang, J. H., and Yang, B. (2015). The photoluminescence mechanism in carbon dots (graphene quantum dots, carbon nanodots, and polymer dots): current state and future perspective. Nano Res. 8, 355-381. doi:10.1007/s12274-014-0644-3

Zhu, Y., Murali, S., Cai, W., Li, X., Suk, J. W., Potts, J. R., et al. (2010). Graphene and graphene oxide: synthesis, properties, and applications. Adv. Mater. 22, 3906-3924. doi:10.1002/adma.201001068

Conflict of Interest Statement: The authors declare that the research was conducted in the absence of any commercial or financial relationships that could be construed as a potential conflict of interest.

Copyright (C) 2015 Guo, Lu and Chen. This is an open-access article distributed under the terms of the Creative Commons Attribution License (CC BY). The use, distribution or reproduction in other forums is permitted, provided the original author(s) or licensor are credited and that the original publication in this journal is cited, in accordance with accepted academic practice. No use, distribution or reproduction is permitted which does not comply with these terms. 